\title{
Nonlinear Model Predictive Control-Based Optimal Energy Management for Hybrid Electric Aircraft considering Aerodynamics- Propulsion Coupling Effects
}

Jinning Zhang, Ioannis Roumeliotis, Argyrios Zolotas

School of Aerospace, Transport and Manufacturing, Cranfield University, Bedfordshire, UK

\begin{abstract}
Hybrid electric propulsion systems have been identified as the feasible solutions for regional jets and narrowbody aircraft to reduce block fuel burn, emissions, and operating cost. Different from land-based vehicles, weight is a major consideration for air transport due to weight-related lift-induced drag penalty. Thus, energy onboard balance, variation in aircraft mass during flight and the aerodynamics-propulsion coupling effects should be considered in hybrid electric aircraft energy management strategy (EMS) while satisfying aircraft maximum take-off weight constraints. In this paper, a Nonlinear Model Predictive Control based optimal energy management scheme (MPC-EMS) has been proposed to minimize the block fuel burn during flight. Firstly, the Artificial Neural Network (ANN) model is adopted with back-propagation algorithm to predict turbofan engine performance with high accuracy and computational efficiency, meanwhile gas turbine-electrical powertrain coupling effects are investigated and analysed for typical operating conditions. Then, by combining a point-mass aircraft dynamic model, nonlinear model predictive control with Cross-Entropy Method (CEM) is proposed to obtain optimal energy management based on a fully coupled aerodynamicspropulsion hybrid electric aircraft model. Besides, this state-constrained optimal control problem is re-formulated as a state-unconstrained problem with penalty function to reduce the computational load. Finally, the proposed MPC EMS algorithm is applied to Boeing 737-800 aircraft with mechanically parallel hybrid electric propulsion configuration to minimize the block fuel burn and compared with the optimization results using global Genetic Algorithm (GA) based EMS. The simulation results indicate that the proposed MPC-EMS can significantly reduce the computational time by more than $97 \%$ while obtaining similar objectives of block fuel burn and emissions reduction.
\end{abstract}

Index Terms- Hybrid electric aircraft, Energy management strategy, Nonlinear model predictive control, Aerodynamicpropulsion coupling, Cross-Entropy Method. 


\section{INTRODUCTION}

The global aircraft fleet consumed over 7\% of oil products (276 million tons of jet fuel) in 2015 and the global air travel demand is expected to grow by about $4.5 \%$ per year in the next two decades [1], [2]. EU's Flightpath 2050 programme calls for a $75 \%$ reduction in carbon emissions per passenger kilometre by 2050 to meet environmental targets [3]. Over the last few years, technological advances in power density and energy capacity of electric systems, e.g., motor and generator, power electronics, and battery, have made electric flight technically and economically feasible and it will make aviation industry's goals of actively limiting the environmental impacts possible [4]. Aircraft electrification is considered as the most promising approach to achieve these goals and tackle climate change. The energy-dense batteries have already brought all-electric solution to a new stage for small, light aircrafts which can carry a few passengers in general aviation sector. However, scaling up to regional jets and narrow-body aircraft, such as Airbus A320 or Boeing 737-sized aircraft, all-electric may not be feasible since weight is a major consideration for air transport, and the identified battery technology level is well-beyond the reach of cutting-edge battery technology [1]. Therefore, hybridelectric propulsion will be the feasible solutions for regional jets and narrow-body aircraft that combine electrification with gas turbine evolutions.

Energy management strategy (EMS) has been extensively explored for ground-based hybrid electric vehicles, which can be generally divided as rule-based EMS, Equivalent Consumption Minimization Strategy (ECMS), global optimization EMS, and Model Predictive Control (MPC) EMS [5]. Table I summarizes the mainstream energy management strategies and methodologies. The rule-based EMS, e.g., charge-depleting/charging sustaining, deterministic rule-based, and fuzzy rule-based EMS are easy and practical to implement and quickly match the pre-designed torque distribution rules, but the performance robustness is poor and is limited by unchangeable set parameters of the rules, the overall vehicle performance is highly dependent on designers' expertise and highly sensitive to mission cycle [5]. Equivalent consumption minimization strategy (ECMS) converts electricity consumption into fuel consumption based on an electricity-to-fuel equivalent factor and obtain instantaneous optimal power distribution by minimizing the equivalent fuel consumption, but it cannot achieve the global fuel-saving performance because the global trip information is not taken into account and the effects of current control actions on the future overall system states is not considered [6]. Nevertheless, this method can be only applicable to single objective optimization problem, other objectives such as emissions, operating costs cannot be considered. To obtain a global optimal fuel saving performance, dynamic programming can be employed for complex, nonlinear models [7], but this approach is computational demanding, and the computational accuracy highly depends on fitness of discretization [8]. Liu et al. [9] proposed a computationoptimized DP-based EMS with prediction horizon to reduce calculation load and ensure the optimization effect. 
Pontryagin's minimum principle (PMP) can provide analytical solution for global optimal solution but is challenging and complicated to enforce complex constraints in complicated nonlinear systems [10]. Model Predictive control (MPC) is widely used in EMS optimization problems, the rolling optimization problem is solved with a prediction horizon at each sampling to ensure optimization accuracy with acceptable computational speed. MPC based EMS has the capability to handle many system constraints simultaneously and can be applicable to a multivariable problem (energy balance of multiple sources of energy) and a multi-objective optimization problem (fuel consumption, energy consumption, emissions, costs, etc.). East et al. [11] proposed a projected interior-point method for solving a convex formulation of MPC EMS in hybrid electric vehicles with nonlinear losses, which can provide high accuracy and is significantly faster than a general convex optimization software CVX. Yang et al. [12] set up a model of stochastic driving behaviours as probability transition matrix and proposed a stochastic MPC framework based on fast rolling optimization using continuation/generalized minimum algorithm. In [13], a nonlinear MPC EMS is proposed for fuel cell hybrid electric vehicle and recurrent neural network was employed to accurately predict fuel cell nonlinear dynamics. He et al. [14] developed a nonlinear MPC EMS with lifetime constraints for fuel cell hybrid electric vehicles by constructing a novel objective function with power slope and temperature.

TABLE I

SUMMARY OF ENERGY MANAGEMENT STRATEGy METHOdOLOGIES

\begin{tabular}{|c|c|c|}
\hline Methodologies & Advantages & Disadvantages \\
\hline $\begin{array}{c}\text { Global optimization EMS } \\
\text { Dynamic programming }(D P), \\
\text { Convex programming }(C P), \\
\text { Pontryagin's Minimum Principle }(P M P), \\
\text { Genetic algorithm }(G A) .\end{array}$ & $\begin{array}{l}\text { Provide a globally optimal solution to the } \\
\text { optimization problem. }\end{array}$ & $\begin{array}{l}\text { Analytical methods are frequently not } \\
\text { applicable for complicated problems with } \\
\text { complex constraints; Strong model } \\
\text { simplification; Require full cycle information; } \\
\text { High computation effort. }\end{array}$ \\
\hline $\begin{array}{c}\text { Rule-based EMS } \\
\text { Deterministic rule-based EMS, } \\
\text { Fuzzy rule-based EMS. }\end{array}$ & Easy to implement, Low computation burden. & $\begin{array}{l}\text { Vehicle performance is determined by } \\
\text { predefined rules, it's highly dependent on } \\
\text { designers' expertise; Highly sensitive to } \\
\text { mission cycle. }\end{array}$ \\
\hline$\frac{\text { Equivalent Consumption Minimization }}{\underline{\text { Strategy (ECMS) }}}$ & Easy to implement. & $\begin{array}{c}\text { Optimal instantaneous equivalent fuel } \\
\text { consumption, cannot guarantee the optimal } \\
\text { aircraft performance at mission level; Single } \\
\text { objective optimization, cannot be expandable } \\
\text { to operating costs, emission, etc. }\end{array}$ \\
\hline $\begin{array}{c}\text { Model Predictive Control EMS } \\
\text { (MPC) }\end{array}$ & $\begin{array}{l}\text { Reduced computation load; Allow the current } \\
\text { timeslot to be optimized, while keeping future } \\
\text { timeslots in account; Handle many system } \\
\text { constraints simultaneously; Applicable to a } \\
\text { multivariable problem (energy balance of multiple } \\
\text { sources of energy); Applicable to a multi-objective } \\
\text { optimization problem. }\end{array}$ & \\
\hline
\end{tabular}

However, hybrid electric aircraft EMS consideration is recognizably different from that of ground vehicles. The mission analysis and performance assessment of aircraft are performed based on the premises of balancing the thrust to drag with the fuel flow and electrical power flow within the set operational and performance constraints defined by the top-level 
requirements [15]. The mission segments are discretized by an energy-based approach with a mission explicitly defined for each step. It involves a large amount of iterations between propulsion system performance module and the aircraft performance module based on a multidisciplinary analysis of aerodynamics, propulsion system performance and weight [16]. Weight is a major consideration for air travel, especially for hybrid electric aircraft, since the additional weight of electrical powertrain and battery energy storage might degrade the integrated aircraft performance due to induced weightrelated drag penalty [17]. Propulsion system electrification and hybridization can definitely improve block fuel burn and emissions at isolated propulsion system level due to electrical power on-take and more efficient operation, but the promising improvements and benefits cannot be guaranteed from the perspectives of integrated aircraft level. Besides, gas turbine fuel flow in-flight also leads to the changes in aircraft mass, and further affects aerodynamics performance, such as lift-dependent drag and thrust demand, especially for regional jets which operates in high altitude with long flight durations. This is reason why a fully coupled propulsion-aerodynamic model with multidisciplinary analysis is required for hybrid electric propulsion system performance assessment. Besides, energy onboard should be equal to mission energy demand, as excessive amount of energy carried induces weight and drag penalty [18]. For hybrid electric aircrafts with dual energy sources, both consumable mass energy sources of fuel and non-consumable mass energy sources of battery should be taken into account. Thus, hybrid electric aircraft EMS should be considered from a global optimization perspective at integrated aircraft level with a fully coupled aerodynamics-propulsion multidisciplinary model, which greatly increases the system complexity and computational load. Thus, the EMS for hybrid electric aircraft is complicated and challenging to implement which is not widely investigated yet. Carlo [19] proposed an energy-optimal power management strategy to reduce energy expenditure by properly setting throttles of internal combustion engine and electric motor for a light single-propeller hybrid electric motor glider. Nakka et al. [20] proposed a combined optimal design and control method using a simultaneous formulatoin of multidisciplinary dynamic system design optimizaion to enable the integration of EMS with hybrid electric propulsoin configuration component sizing. Xie et al. [21] proposed a fuzzy logic based equivalent consumption optimization for hybrid electric unmanned aerial vehicles. However, the above studies focus on small and lightweight aircrafts, which operates in low altitude with short flight durations using internal combustion engine. Weight is not a concern for these lightweight aircraft models. Thus, energy balance, aero-propulsive coupling, and aircraft mass variation is excluded in these works. Donateo et al. [22][23] applied dynamic programming to obtain optimal power-split sequence by assuming a priori knowledge power demand profile, and an online optimizer is further developed on this basis to minimize equivalent consumption minimization strategy considering the desired state of charge and state of health of the battery. Doff-Sotta et al. [24] proposed a convex formulation for optimal energy management in hybrid electric aircraft using MPC strategy. And the available payload is reduced to accommodate the 
additional weight of electrical components and battery storage. However, these studies [22-24] are based on a prioriknowledge thrust or power demand profile by assuming constant aircraft mass for the duration of the flight, which does not consider the variation in aircraft mass caused by fuel burn in flight and aero-propulsive coupling effects. Ang et al. [25] proposed EMS by looping for power-split only in take-off and climb phases, and gas turbine is scaled down for cruise condition for a hybrid turbofan engine powered A320 aircraft on a short-range flight mission. Zamboni et al. [26] proposed a single objective optimization considering aero-propulsive coupling by using a monolithic architecture based on isolated gas turbine and aircraft mission analysis models, then manual iteration is performed between disciplines to finalize the procedure. The above studies [25-26] takes coupled propulsion-aerodynamic multidisciplinary analysis into account, but it leaves design space for further exploration and optimization, and lacks a computationally efficient optimization procedure.

In this study, motivated by the above issues, a nonlinear MPC-based EMS using Cross Entropy Method for hybrid electric aircraft is proposed to achieve an optimal solution for power distribution considering the following competing objectives: 1) to prevent battery excessive discharge; 2) to satisfy aircraft maximum take-off weight (MTOW) constraints 3) to achieve energy balance 4) to minimize the objective function, such as fuel consumption, energy consumption, emissions of carbon emissions $\left(\mathrm{CO}_{2}\right)$ and Nitrogen-oxide $\left(\mathrm{NO}_{\mathrm{x}}\right)$ in flight while maintaining operating limits, e.g., gas turbine structural and temperature limits.

The main contribution of this paper makes the following contributions. Firstly, an ANN gas turbine surrogate model is established, and the gas turbine-electrical powertrain coupling effects are obtained by analysing the pressure-build, corrected core/bypass mass flow and component efficiency at typical operating conditions. Next, a nonlinear MPC-based EMS using Cross Entropy Method and backward induction algorithm is proposed based on a fully coupled aerodynamics-propulsion hybrid electric aircraft model. Meanwhile, this state-constrained problem is re-formulated as a state-unconstrained problem with penalty function to reduce computational load.

The rest of this paper is organized as follows. Section II describes the HEA model, including point-mass aircraft model, ANN gas turbine surrogate model, electrical powertrain model. The Nonlinear Model Predictive Control based EMS is proposed using Cross Entropy Method (CEM) in Section III. The results and discussions of ANN gas turbine surrogate model and the proposed MPC EMS are shown in Section IV. Finally, the conclusions are summarized in Section V.

\section{MODELLING OF PARALLEL HYBRID ELECTRIC AIRCRAFT}

This section establishes aircraft dynamics and hybrid electric propulsion system components models, which will be used to formulate energy management strategy (EMS) problem as a model-based optimization problem. The propulsion 
system of P-HEAs considered in this study is Mechanically Integrated Parallel Hybrid (MIPH) architecture where electrical power on-take is utilized to boost low pressure shaft [27]. A diagram with the main components of the propulsion system is shown in Fig. 1, with fuel (kerosene) as primary energy source and a battery operating as secondary energy source. To assess the block fuel burn and emissions performance of the P-HEA, the details of aircraft dynamics model and propulsion system components model (turbofan engine, motor, battery, etc.) will be given in the following subsections.

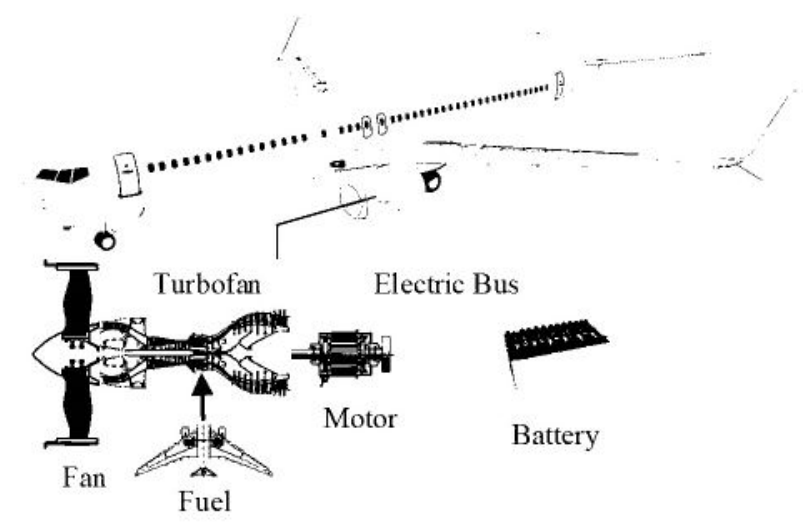

Fig. 1. The propulsion architecture of P-HEA [28]

\section{A. Point-mass aircraft model of P-HEA}

A point-mass aircraft model is used in this study for a fast-time aircraft motion simulation environment, which can be described as Equation (1) [29]:

$$
\frac{d}{d t}\left[\begin{array}{c}
\dot{x} \\
\dot{y} \\
\dot{h} \\
\dot{V} \\
\dot{\psi} \\
\dot{\gamma} \\
\dot{W}
\end{array}\right]=\left[\begin{array}{c}
V \cos (\psi) \cos (\gamma) \\
V \sin (\psi) \cos (\gamma) \\
V \sin (\gamma) \\
\frac{g}{W}[T \cos (\alpha)-D-W \sin (\gamma)] \\
\frac{g}{W V \cos (\gamma)}[T \sin (\alpha)+L] \sin (\mu) \\
\frac{g}{W V}[(T \sin (\alpha)+L) \cos (\mu)-W \cos (\gamma)] \\
-\dot{W}_{f}
\end{array}\right]
$$

Where $x, y, h$ represent the position of aircraft in ground axis coordinated system, $V$ is the aircraft velocity relative to the ground, $\psi, \gamma, \mu$ denote yaw heading angle, pitch/flight path angle and roll bank angle respectively, $W$ is the weight of 
aircraft, $\alpha$ is the angle of attack, $\dot{W}_{f}$ is the engine fuel flow rate, $T, D, L$ are the aerodynamic forces of thrust, drag and lift respectively, $g$ is the constant acceleration of gravity.

The lift and the drag can be calculated by Equation (2):

$$
\begin{aligned}
& L=\frac{1}{2} C_{L}(\alpha, M a, h) \rho S V^{2} \\
& D=\frac{1}{2} C_{D}(\alpha, M a, h) \rho S V^{2}
\end{aligned}
$$

Where $C_{L}, C_{D}$ are lift coefficient and drag coefficient, $\rho$ is the atmosphere density at altitude, and $S$ is reference wing area.

\section{B. Modelling of MIPH propulsion system}

Gas turbine on-design/off-design performance simulation is a complex nonlinear problem to be solved by iteration algorithms. As the gas turbine components and configuration complexity increase and the subsequent iteration variables, nested loops are formulated and need to be solved which is significantly time-consuming [30]. Artificial neural network (ANN) can model highly nonlinear input-output mappings. Once the training of ANNs is conducted, the ANN based surrogate model can rapidly and accurately estimate gas turbine performance without iteration. The ANN has been identified as a cost-effective and user-friendly tool for gas turbine system performance analysis, health monitoring, prognostics, and diagnostics [31]. As shown in Fig. 1, MIPH propulsion system is composed of gas turbine, motor, and battery. Considering highly nonlinear characteristics of gas turbine operation, an artificial neural network (ANN) is employed with back-propagation algorithm to predict turbofan engine performance with high accuracy and computational efficiency. According to the gas turbine subsystem states $\boldsymbol{G}=\left[h, M a, F_{N}\right]^{T}$ and control variable $\boldsymbol{u}=\left[H p_{L P T}\right]$, the ANN framework for gas turbine performance estimation model is defined as 4-10-10-6 and is shown in Fig. 2, containing an input-layer, two hidden-layers, and an output-layer [32] [33].

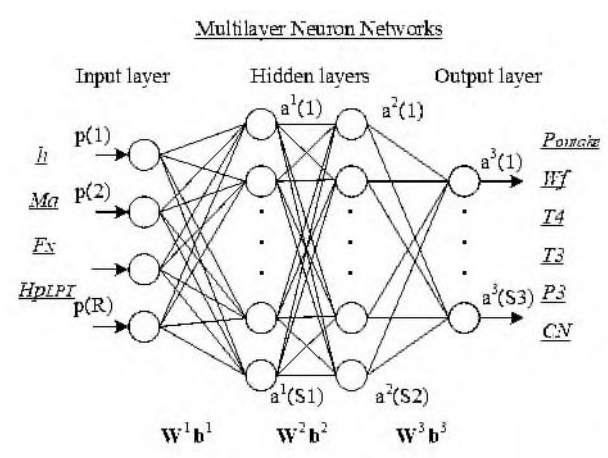


Fig. 2. ANN based gas turbine performance model

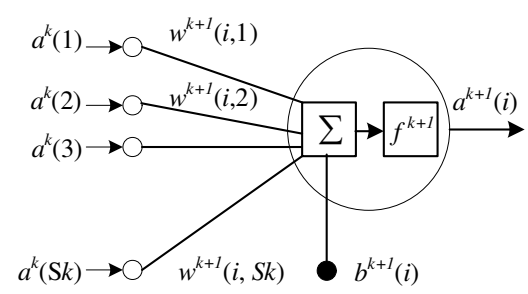

Fig. 3. The input and output of a neuron

The input and output of the ANN framework is given in Table II.

TABLE II

THE INPUT AND OUTPUT OF THE ANN FRAMEWORK

\begin{tabular}{ll}
\hline \hline Parameters & Description \\
\hline$h$ & Flight altitude \\
$M a$ & Flight Mach number \\
$F_{N}$ & Design net thrust demand \\
$H p_{L P T}$ & Degree of hybridization of power on low pressure shaft \\
$P_{\text {ontake }}$ & Power on-take on low pressure shaft \\
$W f$ & Fuel flow rate \\
$T 4$ & Turbine entry temperature \\
$T 3$ & Burner inlet temperature \\
$P 3$ & Burner inlet pressure \\
$C N$ & Low pressure shaft non-dimensional rotational speed \\
\hline \hline
\end{tabular}

As shown in Fig. 3, a neuron with input vector $\mathbf{a}^{\mathbf{k}}=\left[a^{k}(1), a^{k}(2), \cdots a^{k}(S k)\right]$ are weighted by elements $w^{k+1}(i, 1), w^{k+1}(i, 2), \cdots, w^{k+1}(i, S k)$ of the weight matrix respectively with a bias $b^{k+1}(i)$. The output of the neuron $i$ in layer $k+1$ can be described as Equation (3):

$$
a^{k+1}(i)=f^{k+1}\left(\sum_{j=1}^{S k} w^{k+1}(i, j) a^{k}(j)+b^{k+1}(i)\right)
$$

Where $a^{k+1}(i)$ is the output of the neuron $i$ in layer $k+1, f^{k+1}$ is activation function. In this study, the Rectified Linear Unit (ReLU) activation function is used, which allows faster and effective training of deep neural architectures on large and complex datasets compared to sigmoid function or similar activation functions.

The system matrix is given as Equation (4):

$$
\begin{aligned}
& \mathbf{a}^{0}=\mathbf{p} \\
& \mathbf{a}^{k+1}=\mathbf{f}^{k+1}\left(\mathbf{W}^{k+1} \mathbf{a}^{k}+\mathbf{b}^{k+1}\right)
\end{aligned}
$$


Herein, weight vectors and biases of network is written as Equation (5),

$$
\begin{aligned}
& \mathbf{W}^{1}=\left[\begin{array}{ccc}
w^{1}(1,1) & \cdots & w^{1}(1, R) \\
\vdots & \ddots & \vdots \\
w^{1}(S 1,1) & \cdots & w^{1}(S 1, R)
\end{array}\right] \\
& \mathbf{b}^{1}=\left[\begin{array}{lll}
b^{1}(1) & \cdots & b^{1}(S 1)
\end{array}\right] \\
& \mathbf{W}^{2}=\left[\begin{array}{ccc}
w^{2}(1,1) & \cdots & w^{2}(1, S 1) \\
\vdots & \ddots & \vdots \\
w^{2}(S 2,1) & \cdots & w^{2}(S 2, S 1)
\end{array}\right] \\
& \mathbf{b}^{2}=\left[\begin{array}{llll}
b^{2}(1) & \cdots & b^{2}(S 2)
\end{array}\right] \\
& \mathbf{W}^{3}=\left[\begin{array}{ccc}
w^{3}(1,1) & \cdots & w^{3}(1, S 2) \\
\vdots & \ddots & \vdots \\
w^{3}(S 3,1) & \cdots & w^{3}(S 3, S 2)
\end{array}\right] \\
& \mathbf{b}^{3}=\left[\begin{array}{llll}
b^{3}(1) & \cdots & b^{3}(S 3)
\end{array}\right]
\end{aligned}
$$

Once the ANN framework and neuron transfer functions are determined, weight matrixes and biases are trained and adjusted by the collected dataset of input-output pairs, until training error $E_{\mathrm{m}}$ meets terminal condition as Equation (6).

$$
E_{\mathrm{m}}=\frac{1}{2} \sum_{q=1}^{Q}\left(\mathbf{t}_{q}-\mathbf{a}_{q}^{3}\right)^{T}\left(\mathbf{t}_{q}-\mathbf{a}_{q}^{3}\right)
$$

Where $Q$ is a total number of training data, $\mathbf{t}=\left[\tilde{P}_{\text {ontake }}, \tilde{\dot{W}}_{f}, \tilde{T}_{4}, \tilde{T}_{3}, \tilde{P}_{3}, \tilde{N}_{C N}\right]^{\mathrm{T}}$ is target output vector which consists of $P_{\text {ontake, }}$ power on-take for low pressure turbine (LPT), $\dot{W}_{f}$, gas turbine fuel flow rate, $T_{4}$, turbine entry temperature, $T_{3}, P_{3}$ are burn inlet temperature and pressure, $N_{C N}$ is non-dimensional rotational speed of LPT. These gas turbine operating characteristics will be used to estimate emissions performance. To minimize training error, the approximate steepest gradient descent algorithm with momentum term is applied. The training process can be described in matrix form as Equation (7),

$$
\left\{\begin{array}{l}
\Delta W(n)=-\alpha \cdot \frac{\partial E_{\mathrm{m}}(n)}{\partial W(n)}+\eta \cdot \Delta W(n-1) \\
W(n+1)=W(n)+\Delta W(n)
\end{array}\right.
$$

Where $n$ denotes the training iteration step, $\alpha$ and $\eta$ represent learning and momentum factor respectively. The training process is assumed to converge when the training error is reduced to pre-determined training objective error $e_{\mathrm{m}}$. The effectiveness of ANN gas turbine performance model is validated in Section V. 
A rubber motor efficiency model, as shown in Fig. 4, is proposed for electric aircraft conceptual design studies, which is used to represent a hypothetical motor that has not been built or designed [34]. The motor efficiency is defined as Equation (8):

$$
\eta_{\text {Mot }}=\frac{P_{\text {Motor }}}{P_{\text {Motor }}+P_{\text {Loss }}}=\frac{w \cdot Q}{w \cdot Q+P_{\text {Loss }}}
$$

Where $\eta_{\text {Mot }}$ denotes motor efficiency, $w$ is motor rotational speed, $Q$ is torque and $P_{\text {Loss }}$ is power loss.

The motor power loss is expressed as Equation (9):

$$
P_{\text {Loss }}=C_{0}+C_{1} w+C_{2} w^{3}+C_{3} Q^{2}
$$

Where $C_{i}$ is served as the constants of proportionality for each loss term. Specialized to represent peak efficiency, $C_{i}$ coefficients are derived and presented as Equation (10):

$$
C_{0}=k_{0} \frac{\hat{w} \hat{Q}}{6} \frac{1-\hat{\eta}}{\hat{\eta}}, C_{1}=\frac{-3 C_{0}}{2 \hat{w}}+\frac{\hat{Q}(1-\hat{\eta})}{4 \hat{\eta}}, C_{2}=\frac{C_{0}}{2 \hat{w}^{3}}+\frac{\hat{Q}(1-\hat{\eta})}{4 \hat{\eta} \hat{w}^{2}}, C_{3}=\frac{\hat{w}(1-\hat{\eta})}{2 \hat{Q} \hat{\eta}}
$$

Where $k_{0}$ serves as a convenience factor for specifying a parametric motor model, $\hat{\eta}, \hat{w}, \hat{Q}$ are peak efficiency, peak efficiency speed and torque.

The operating limitations on maximum torque, power and speed are described as ratios on the $\hat{w}, \hat{Q}$. The ratios are defined as Equation (11):

$$
k_{Q}=\frac{Q_{\text {rated }}}{\hat{Q}}, k_{P}=\frac{P_{\text {rated }}}{\hat{w} \hat{Q}}, k_{w}=\frac{w_{\text {limit }}}{\hat{w}}
$$

With this approach, motor efficiency can be easily estimated by specifying design parameters $\left(\hat{w}, \hat{Q}, \hat{\eta}, k_{0}, k_{Q}, k_{P}, k_{w}\right)$, which is sufficient for aircraft performance calculation in early stages. 


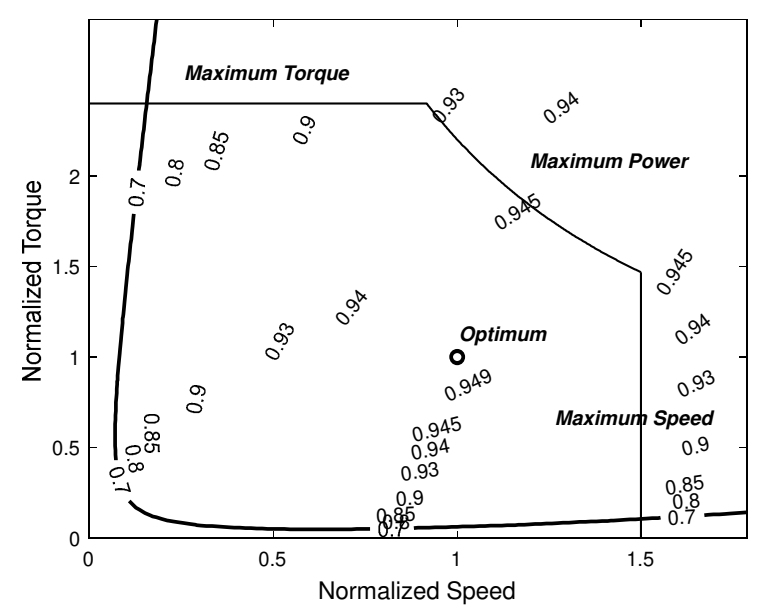

Fig. 4. An example of rubber motor efficiency model

An equivalent circuit model [35] is used for Li-ion battery pack modelling described as Equation (12):

$$
\left\{\begin{array}{l}
\eta_{b a t}=\frac{P_{b a t}}{P_{E S}}=\frac{V_{b} \cdot I_{b}-I_{b}^{2} \cdot\left(R_{d}+R_{0}\right)}{V_{b} \cdot I_{b}} \\
S \dot{O} C=\frac{-V_{b}+\sqrt{V_{b}^{2}-4 \cdot P_{b a t} \cdot\left(R_{d}+R_{0}\right)}}{2 \cdot C_{\mathrm{Ah}} \cdot\left(R_{d}+R_{0}\right)}
\end{array}\right.
$$

Where $\eta_{b a t}$ denote battery pack operating efficiency, $P_{E S}$ is electrical energy storage power consumed, $P_{b a t}, I_{b}, V_{b}, R_{d}$, $R_{0}, C_{\mathrm{Ah}}$ represent output power, open circuit voltage, dynamic resistance, constant resistance and capacity of the batteries respectively.

In MIPH configuration, electrical power from battery pack is utilized to boost low pressure shaft as requested by gas turbine operation. Assuming constant efficiency of converters $\eta_{\text {Conv }}$ and transmission lines $\eta_{\text {Trans }}$, gas turbine and electrical powertrain is linked as Equation (13):

$$
P_{E S}=\frac{P_{\text {Motor }}}{\eta_{\text {Mot }} \eta_{\text {Conv }} \eta_{\text {Trans }} \eta_{\text {Bat }}}=\frac{P_{\text {ontake }}}{\eta_{\text {Mot }} \eta_{\text {Conv }} \eta_{\text {Trans }} \eta_{\text {Bat }}}
$$

\section{NONLINEAR MPC BASED ENERGY MANAGEMENT STRATEGY}

\section{A. Problem formulation of Energy management strategy}

In this study, the Nonlinear MPC based optimal energy management scheme is constructed as shown in Fig. 5. The purpose of the EMS is to achieve an optimal solution for power distribution considering the following competing objectives: 1) to prevent battery excessive discharge; 2) to satisfy aircraft maximum take-off weight (MTOW) constraints 
3) to achieve energy balance: onboard energy is equal to flight mission energy demand 4) to minimize the objective function, such as fuel consumption, energy consumption, emissions of carbon dioxide $\left(\mathrm{CO}_{2}\right)$ and Nitrogen-oxide $\left(\mathrm{NO}_{\mathrm{x}}\right)$ in flight while maintaining operating limits, e.g., gas turbine structural and temperature limits.

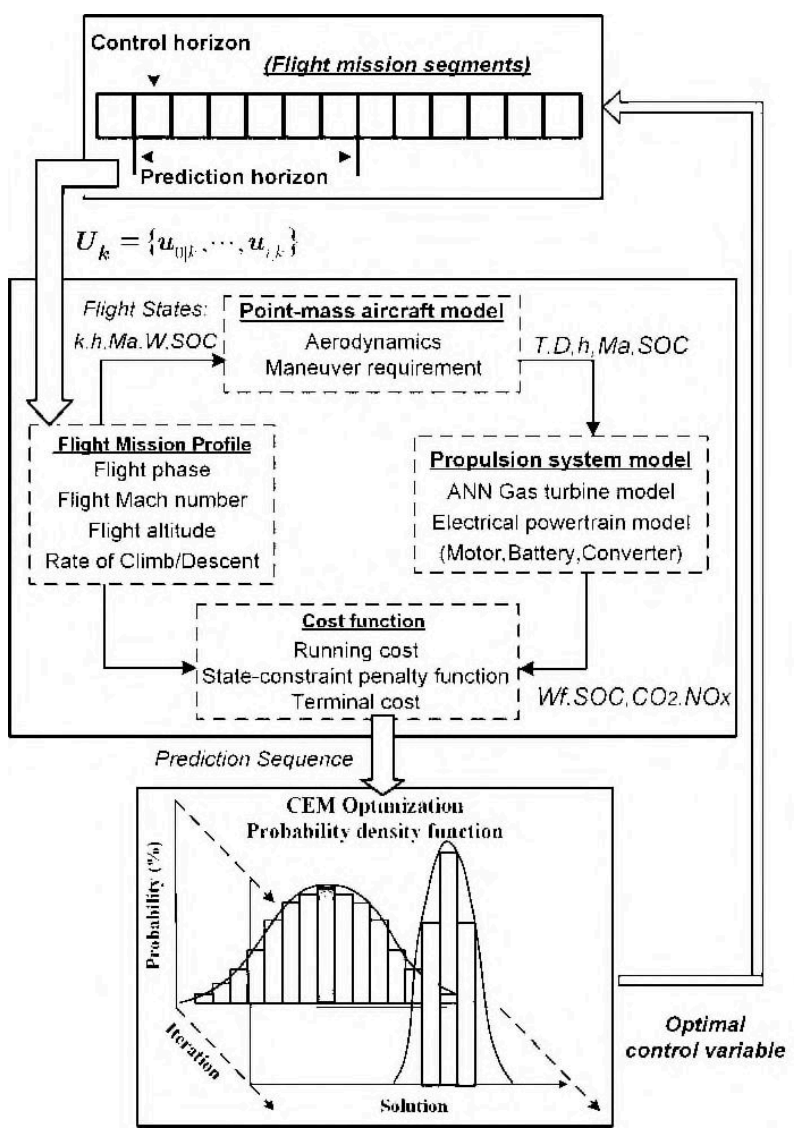

Fig. 5. MPC-based EMS optimization using Cross-Entropy Method

The proposed Nonlinear MPC optimal control problem can be solved by three steps: system state estimation and prediction, objective function evaluation, and optimal control action application [38]. A nonlinear model of P-HEA with MIPH propulsion configuration is established to estimate and predict flight dynamics, gas turbine and electrical powertrain behaviours. The receding horizon optimization solves the optimal control problem at each sampling segment using Cross Entropy Method (CEM) to obtain an optimal control sequence of prediction horizon. At the next sampling segment, only the first control action in optimal control sequence will be taken, and the optimal control problem will be solved successively by receding horizon optimization.

Given a prior flight mission, the dynamic process of P-HEA with MIPH propulsion configuration can be described as a flight-segment-related model. The discrete-segment state space is described as Equation (14):

$$
\boldsymbol{x}(k+1)=\phi(\boldsymbol{x}(k), \boldsymbol{u}(k)), k \hat{\mathrm{I}} \mathrm{N},
$$


Where $\boldsymbol{x}=[h, M a, W, D, T, S O C, \delta]^{\mathrm{T}}$ is the state vector of flight altitude, Mach number, instantaneous aircraft weight, drag, thrust demand, battery SOC and segment flight duration at discrete-segment instant $k$ respectively, $\phi$ is a nonlinear function which assigns the successor state $\boldsymbol{x}(k+1)$ given $\boldsymbol{x}(k)$ and the control input $\boldsymbol{u}(k)$. And $\boldsymbol{u}=[h p]$ is control input which represents hybridization of power on turbofan low power turbine. The constraints of aircraft maximum take-off weight (MTOW) constraints and battery SOC operating range are $W \leq W_{\text {MTOW }}$, and $S O C_{\min } \leq S O C \leq S O C_{\max }$

For each segment, flight altitude $h$ and Mach number $M a$ are given with constant velocity constant climb/descent rate in flight mission profile as show in Fig. 6. Flight segment duration $\delta$ is calculated based on the prior flight mission profile and point mass aircraft model.

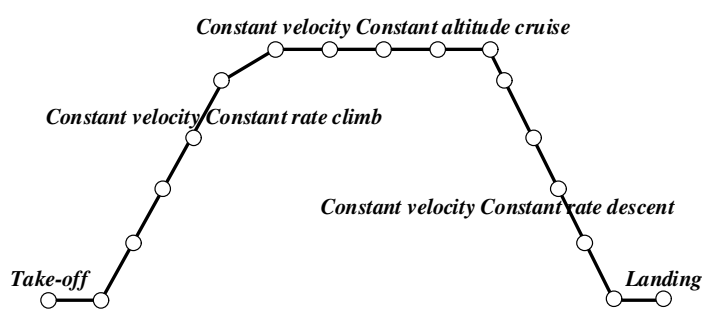

Fig. 6. Flight mission profile

Assuming a generalized propulsion system with multiple thrust sources $M$, block fuel burn $\mathbf{l}^{\text {fuel }}(k)$ and energy consumption $\mathbf{l}^{\text {energy }}(k)$ in $k$-th flight segment can be described as Equation (15) and (16):

$$
\begin{gathered}
\mathbf{l}^{\text {fuel }}(k)=\sum_{m=1}^{M} \dot{W}_{f}^{m}(k) \cdot \delta(k) \\
\mathbf{l}^{\text {energy }}(k)=\sum_{m=1}^{M}\left(\dot{W}_{f}^{m}(k) \cdot F H V+\frac{P_{\text {ontake }}^{m}(k)}{\eta_{\text {Mot }}^{m}(k) \eta_{\text {Conv }}^{m}(k) \eta_{\text {Trans }}^{m}(k) \eta_{\text {Bat }}^{m}(k)}\right) \cdot \delta(k)
\end{gathered}
$$

Where $F H V$ refers to fuel heating value of kerosene, typically $43.69 \mathrm{MJ} / \mathrm{kg}$.

P3T3 method [36] as a semi-empirical correlations approach is used to estimate aircraft propulsion system NOx emissions given engine internal gas path parameters $\dot{W}_{f} T_{3} P_{3}$ at combustor diffuser inlet. Emission index $(\mathrm{g}$ NOx $/ \mathrm{kg}$ fuel) of NOx caused by block fuel burn are given as Equation (17):

$$
E I_{N O x}=\left(8.4+0.0209 e^{0.0082 T_{3}}\right)\left(\frac{P_{3}}{3000}\right)^{0.4} \cdot e^{19(0.006344-h)}
$$


In this study, direct $\mathrm{CO}_{2}$ emissions from block fuel burn and indirect $\mathrm{CO}_{2}$ emissions caused by electricity production are both considered. On-board batteries can provide electrical power without direct carbon emissions, so that carbon emissions can be alleviated more effectively on the ground-based power plants than at altitude, especially by increasing the utilization of clean and renewable energy sources such as solar, wind and hydrogen for electricity production. Emission index $\left(\mathrm{g} \mathrm{CO}_{2} / \mathrm{kg}\right.$ fuel) of block fuel burn and emission index of $\mathrm{CO}_{2}\left(\mathrm{~g} \mathrm{CO}_{2} / \mathrm{kWh}\right)$ caused by electricity production in UK [37] are given as Equation (18):

$$
E I_{\mathrm{CO} 2_{-} \text {fuel }}=3159 \quad \mathrm{EI}_{\mathrm{CO} 2_{-} \text {elec }}=130
$$

Based on emission indexes, the emissions in $k$-th flight segment can be described as Equation (19-20):

$$
\begin{gathered}
\mathbf{l}^{\mathrm{CO}_{2}}(k)=\sum_{m=1}^{M}\left(\dot{W}_{f}^{m}(k) \cdot E I_{\mathrm{CO} 2 \__{-} \text {fuel }}^{m}(k)+\frac{P_{\text {ontake }}^{m}(k)}{\eta_{\text {Mot }}^{m}(k) \eta_{\text {Conv }}^{m}(k) \eta_{\text {Trans }}^{m}(k) \eta_{\text {Bat }}^{m}(k)} \cdot E I_{\text {CO2_elec }}^{m}(k)\right) \cdot \delta(k) \\
\mathbf{l}^{\text {NOx }}(k)=\left(\sum_{m=1}^{M} \dot{W}_{f}^{m}(k) \cdot E I_{N O x}^{m}(k)\right) \cdot \delta(k)
\end{gathered}
$$

Therefore, the cost function in $k$-th segment is defined as the weighted sum of optimization objectives in Equation (21):

$$
\boldsymbol{L}_{1}(\boldsymbol{x}, \boldsymbol{u})=\lambda_{1}^{f} \mathbf{1}^{\text {fuel }}+\lambda_{1}^{e} \mathbf{1}^{\text {energy }}+\lambda_{1}^{C O_{2}} \mathbf{1}^{C O_{2}}+\lambda_{1}^{N O x} \mathbf{l}^{N O x}
$$

Where $\lambda_{1}^{f}, \lambda_{1}^{e}, \lambda_{1}^{C O_{2}}, \lambda_{1}^{N O x}$ are weight coefficients for performance indexes of block fuel burn, energy consumption, $\mathrm{CO}_{2}$ emissions and NOx emissions respectively. In the future research work, the weight coefficients are designed to be dynamically tuned in each flight segment to prioritize the specific objectives, in order to minimize pollutant emissions during departure and arrivals over communities near the airports. In this paper, the sub-objective functions are normalized and the weight coefficients are set as equal to be 0.25 for individual sub-objectives of block fuel burn, energy consumption, $\mathrm{CO} 2$ emissions and NOx emissions.

The propulsion system components have physical constraints to ensure a safe operation and a long-term stable work, such as gas turbine structural and temperature limits. In this study, the state-constrained optimal control problem will be converted into a state-unconstrained problem with penalty function, which can dramatically reduce the computational time [38]. The proposed penalty functions hardly work in normal operating conditions. However, when the gas turbine operating temperature or non-dimensional rotational speed are close to their operating limits, the penalty functions will be rapidly increase [38]. The penalty function in each segment is designed as Equation (22): 


$$
\boldsymbol{L}_{2}(\boldsymbol{x}, \boldsymbol{u})=\lambda_{2}^{T} \ln \left(\frac{T_{G \boldsymbol{T}, \max }-T_{4}(k)}{T_{G \boldsymbol{T}, \max }-T_{G T, \min }}\right)+\lambda_{2}^{C N} \ln \left(\frac{N_{C N, \max }-N_{C N}(k)}{N_{C N, \max }-N_{C N, \min }}\right)
$$

Where $\lambda_{2}^{T}, \quad \lambda_{2}^{C N}$ are performance coefficients for gas turbine operating temperate limit and LP shaft rotational speed respectively, $T_{G T, \min }, T_{G T, \max }$ are gas turbine operating temperate limits and $N_{C N \text {, min }}, N_{C N \text {, max }}$ are LP shaft non-dimensional rotational speed limits.

However, especially for hybrid electric aircrafts, aircraft energy onboard must be equal to mission energy demand for a prior flight mission, otherwise the excessive amount of energy onboard would largely induce weight and drag penalty and inversely deteriorate fuel consumption and emissions performance. Therefore, to achieve energy balance, the backward induction algorithm will be applied to obtain the optimal solution and avoid iterative algorithm with high computational load. The optimal control problem is decomposed into a sequence of subproblems that are solved recursively backward in discrete segment from final flight segment (landing) to the first (take-off) [7].

To satisfy the aircraft maximum take-off weight (MTOW) constraints and prevent battery pack over-discharge, the terminal state-constrained optimal control problem is converted into a terminal state-unconstrained problem with penalty function as Equation (23),

$$
\boldsymbol{F}(\boldsymbol{x})=\lambda_{3}^{M T O W} \cdot \ln \left(\frac{W_{\mathrm{MTOW}}-W}{W_{\mathrm{MTOW}}}\right)+\lambda_{3}^{S O C} \cdot \ln \left(\frac{S O C_{\max }-S O C}{S O C_{\max }-S O C_{\min }}\right)
$$

Where $\lambda_{3}^{\text {MTOW }}, \lambda_{3}^{\text {SOC }}$ are performance coefficients for aircraft maximum take-off weight and battery SOC limits respectively, $W_{\text {MTоw }}$ is maximum take-off weight and $S O C_{\min }, S O C_{\max }$ battery $\mathrm{SOC}$ operating limits. The penalty function is a continuous function which can gradually increase as the state variable approaches the limits [38]. The proposed penalty functions hardly work in normal operating conditions. However, when the state variables are close to their limits, the penalty functions will be rapidly increased to effectively avoid constraints violations.

The nonlinear system dynamics model is re-written as $\boldsymbol{x}_{i+1 \mid k}=\phi\left(\boldsymbol{x}_{i \mid k}, \boldsymbol{u}_{i \mid k}\right), i \in\{0, \cdots, N-1\}, k \hat{\mathrm{I}} \mathrm{N}$. The total stage cost is the combination of performance cost function and state-constrained penalty function, $\boldsymbol{L}\left(\boldsymbol{x}_{i \mid k}, \boldsymbol{u}_{i \mid k}\right)=\boldsymbol{L}_{1}\left(\boldsymbol{x}_{i \mid k}, \boldsymbol{u}_{i \mid k}\right)+$ $\boldsymbol{L}_{2}\left(\boldsymbol{x}_{i \mid k}, \boldsymbol{u}_{i \mid k}\right)$. By defining the sequence of predicted control inputs as $\boldsymbol{U}_{\boldsymbol{k}}=\left\{\boldsymbol{u}_{0 \mid k}, \cdots, \boldsymbol{u}_{i \mid k}\right\}$ yields:

$$
\gamma_{k}^{*}=\min _{\boldsymbol{U}_{k}} \boldsymbol{J}\left(\boldsymbol{x}_{0 \mid k}, \boldsymbol{U}_{\boldsymbol{k}}\right)=\min _{\boldsymbol{U}_{\boldsymbol{k}}}\left\{\boldsymbol{F}\left(\boldsymbol{x}_{N \mid k}\right)+\sum_{i=0}^{N-1} \boldsymbol{L}\left(\boldsymbol{x}_{i \mid k}, \boldsymbol{u}_{i \mid k}\right)\right\}
$$


Where $\boldsymbol{x}_{0 \mid k}=\boldsymbol{x}(k), \boldsymbol{u}_{0 \mid k}=\boldsymbol{u}(k), \boldsymbol{F}$ is the terminal cost, $\boldsymbol{L}$ is the stage cost, $\gamma_{k}^{*}$ is the optimal value of cost function. According to the Receding Horizon Optimization process, the Nonlinear MPC optimal control problem will be solved by Cross Entropy Method (CEM).

\section{B. Cross-Entropy Method for Optimization}

In this study, the Cross-Entropy Method (CEM) is applied to solve a deterministic optimization problem using a parameterized probability distribution. The main idea of CEM is to find the parameter vector of probability distribution function to minimize the distance between importance sampling distribution and optimal distribution with zero variance [39][40][41].

In each iteration of cross-entropy, a population of solutions $\boldsymbol{X}_{1}, \ldots, \boldsymbol{X}_{N}$ is generated from a probability density function $f\left(\cdot, v_{t}\right)$. After evaluating all the solutions in this population $\boldsymbol{J}\left(\boldsymbol{x}_{0 \mid k}, \boldsymbol{X}_{1}\right) \cdots \boldsymbol{J}\left(\boldsymbol{x}_{0 \mid k}, \boldsymbol{X}_{N}\right)$, the elite solutions are selected based on the threshold to determine the elite solutions, $\gamma_{t}$. The threshold is defined as the $(1-\rho)$ quantile of the performance values with rarity parameter $\rho$. Based on the elite solutions $\Omega_{\boldsymbol{t}}=\left\{\boldsymbol{X}_{i}: \boldsymbol{J}\left(\boldsymbol{x}_{0 \mid k}, \boldsymbol{X}_{i}\right) \leq \boldsymbol{\gamma}_{t}\right\}$, the parameters of probability density function $v_{t+1}$ are updated by minimizing the Kullback-Leibler divergence between $f\left(\cdot, v_{t}\right)$ and $f\left(\cdot, v_{t+1}\right)$ with a linear parameter smoothing procedure as Equation (25):

$$
\begin{aligned}
& \hat{\boldsymbol{v}}_{t+1}=\underset{\boldsymbol{v}}{\arg \max } \sum_{i=1}^{N} I_{\left\{\boldsymbol{J}\left(\boldsymbol{x}_{0 \mid k}, \boldsymbol{X}_{i}\right) \leq \gamma_{t}\right\}} \ln f\left(\boldsymbol{X}_{i}, \boldsymbol{v}\right) \\
& \boldsymbol{v}_{t+1}=\alpha \cdot \hat{\boldsymbol{v}}_{t+1}+(1-\alpha) \boldsymbol{v}_{t}, \alpha \in(0,1]
\end{aligned}
$$

Where $I$ is the indicator function, $\alpha$ is the smoothing parameter to enhance numerical stability. High value of smoothing parameter will provide fast convergence, while a smaller smoothing parameter enables more exploration and increases the chance to converge to the global optimum.

The terminal criteria are that the sequence of tuples $\left\{\left(\gamma_{t}, v_{t}\right)\right\}$ converge to the neighbourhood of the optimal tuple $\left(\gamma^{*}, v^{*}\right)$. In this study, the probability density function is given in the form of Gaussian distribution as $\hat{v}_{t}=\left[\hat{\mu}_{t}, \hat{\Sigma}_{t}\right]$,

where $\hat{\mu}_{t}, \hat{\Sigma}_{t}$ denote mean vector and variance vector respectively. Therefore, the parameter vector $v_{t}$ will be updated as Equation (26-27): 


$$
\begin{gathered}
\hat{\mu}_{t}=\frac{1}{M} \sum_{i \in \Omega_{t}} \boldsymbol{X}_{i} \\
\hat{\Sigma}_{t}=\frac{1}{M} \sum_{i \in \Omega_{t}}\left(\boldsymbol{X}_{i}-\hat{\mu}_{t}\right)\left(\boldsymbol{X}_{i}-\hat{\mu}_{t}\right)^{T}
\end{gathered}
$$

\section{RESULTS AND DISCUSSIONS}

\section{A. Validation of ANN gas turbine surrogate model}

Cranfield in-house gas turbine performance simulation software TurboMatch is used to obtain turbofan engine CFM56-7 on-design/off-design performance as training and validation datasets. The gas turbine design parameters of CFM56-7 are listed in Table III.

TABLE III

CFM56-7 DESIGN PARAMETERS [42]

\begin{tabular}{lll}
\hline \multicolumn{1}{c}{ Parameters } & \multicolumn{1}{c}{ Value } & Units \\
\hline Flight altitude $h$ & 10668.0 & $\mathrm{~m}$ \\
Flight Mach number $M a$ & 0.785 & - \\
Design net thrust demand $F_{N}$ & 25000 & $\mathrm{~N}$ \\
Turbine inlet temperature $T_{4}$ & 1449.18 & $\mathrm{~K}$ \\
Air mass flow & 143.94 & $\mathrm{~kg} / \mathrm{s}$ \\
Bypass ratio & 5.37 & - \\
Fan DP pressure ratio & 1.533 & - \\
Fan DP isentropic efficiency & 0.85 & - \\
LP compressor DP pressure ratio & 3.16 & - \\
LP compressor isentropic efficiency & 0.891 & - \\
HP compressor DP pressure ratio & 6.75 & - \\
HP compressor DP isentropic efficiency & 0.874 & - \\
Combustion efficiency & 0.999 & - \\
HP turbine DP isentropic efficiency & 0.915 & - \\
LP turbine DP isentropic efficiency & 0.926 & - \\
\hline \hline
\end{tabular}

To enhance the ANN network training performance, feature-wise normalization is performed in data pre-processing to process input data with each feature independently into a standard normal distribution. After that, the ANN model is trained by back-propagation algorithm. For data collection, both training and validation datasets cover the whole operational range of the gas turbine system. The key model parameters of ANN model and dataset are listed in Table IV.

TABLE IV

ANN MODEL KEY PARAMETERS

\begin{tabular}{ll}
\hline \multicolumn{1}{c}{ Parameters } & Values \\
\hline Flight altitude $h$ & {$[0,11000]$} \\
Flight Mach number $M a$ & {$[0,0.8]$} \\
Design net thrust demand $F_{N}$ & {$[0,25000]$}
\end{tabular}




$\begin{array}{ll}\text { Hybridization of power on LPT } H p_{L P T} & {[0,1.0]} \\ \text { Training/Validation } & 80 \% / 20 \% \\ \text { The size of training dataset } & 25000 \\ \text { Neural network } & \text { MLP } \\ \text { Hidden layer number } & 2 \\ \text { Hidden layer neuron } & 20 \\ \text { Activation function } & \text { ReLU } \\ \text { Maximum Epochs } & 10000 \\ \text { Initial } \mu & 0.001 \\ \beta & 10\end{array}$

Fig. 7 shows regression performance and error distribution of ANN gas turbine surrogate model. The R-squared $\left(\mathrm{R}^{2}\right)$ parameters for fuel flow, power on-take, $\mathrm{T}_{4}, \mathrm{~T}_{3}, \mathrm{P}_{3}$ and $\mathrm{CN}$ are $0.9994,0.9984,0.9961,0.9990,0.9993,0.9995$ respectively, indicating the proposed ANN surrogate model can accurately estimate the gas turbine performance while the error distributions are generally symmetric.
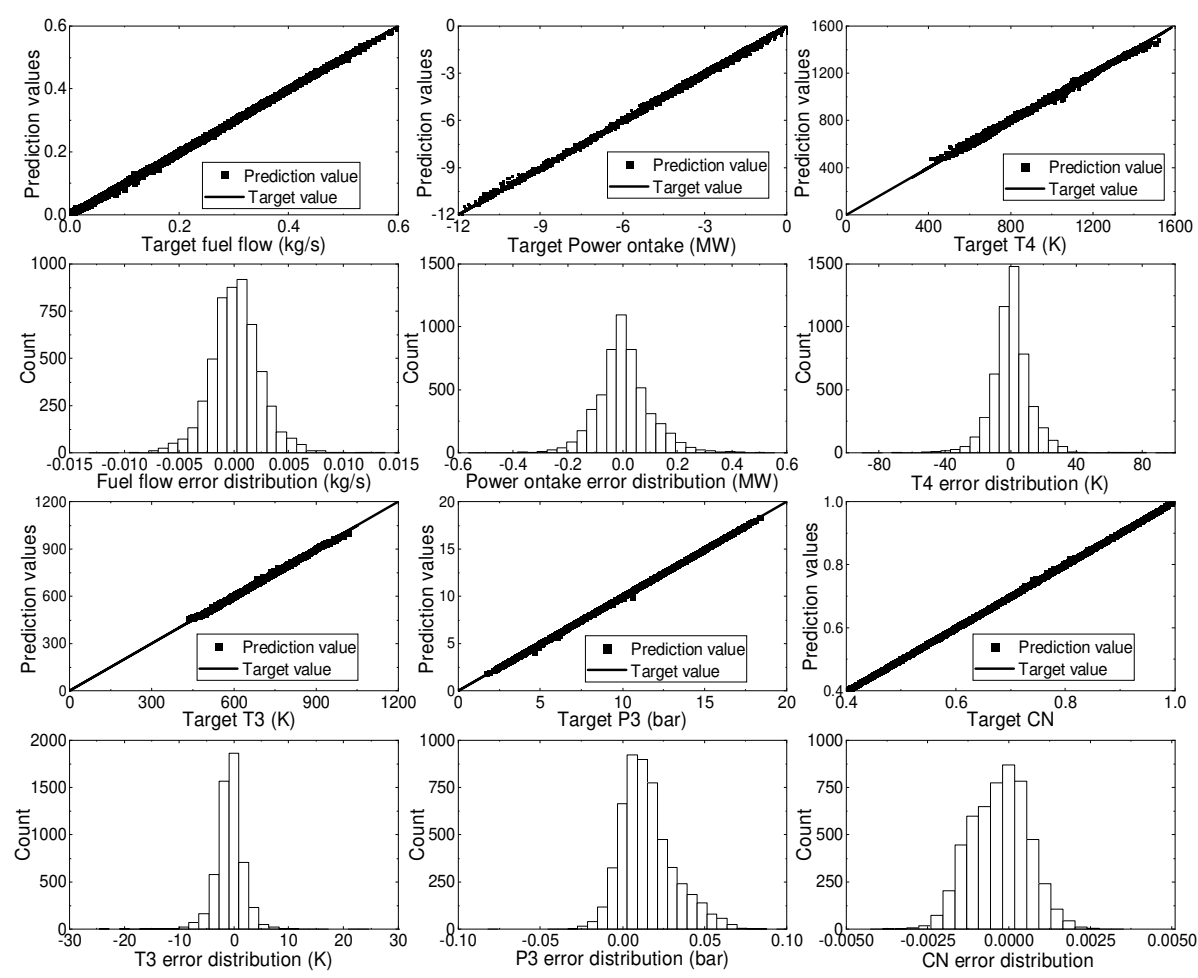

Fig. 7. Relative error of ANN gas turbine model

Table V compares runtime of ANN-based gas turbine surrogate model and Turbomatch for validation dataset. The result indicates that when running for same validation dataset, ANN-based gas turbine performance model can save computational time by $98.60 \%$. ANN-based gas turbine surrogate model will significantly reduce runtime of mission analysis and optimization process. 
TABLE V

RunTIME OF ANN-BASED GAS TURBINE MOdEL AND TURBOMATCH

\begin{tabular}{cl}
\hline \hline & Runtime (s) \\
\hline ANN gas turbine model & 2.72233 \\
Turbomatch & 194.74478 \\
\hline \hline
\end{tabular}

\section{B. Performance analysis of hybrid electric propulsion system}

Table VI lists the flight conditions and thrust of representative steady-state operating points: Takeoff, Top of Climb (TOC) and Cruise, to assess engine performance and investigate gas turbine-electrical powertrain coupling effects under different hybridization of power on LP shaft. The $H p_{L P T}$ ranges from 0.0 to 1.0 with increment of 0.2 .

TABLE VI

TYPICAL OPERATING POINT FOR BOEING 737-SIZE AIRCRAFT

\begin{tabular}{clll}
\hline \hline Operating point & Takeoff & TOC & Cruise \\
\hline Mach Number (-) & 0.25 & 0.78 & 0.78 \\
Altitude (m) & 0 & 10688 & 10688 \\
Thrust (kN) & 96.9 & 31 & 23.3 \\
\hline \hline
\end{tabular}

The gas turbine operation of overall pressure ratio, pressure build-up and core/bypass mass flow are noticeably affected due to components re-matching effects as show in Fig. 8. In general, both fan bypass and low pressure compressor (LPC) operates at higher rotational speed with hybridization. A significant improvement on LPC component efficiency can be noticed while fan bypass operates at lower component efficiency region. However, in TOC, applying hybridization will significantly increase the LP drive rotational speed. LPC is highly likely to occur overspeed when the $H p_{L P T}$ is close to 0.4. Thus, a limit on hybridization of power should be considered to avoid overspeed and ensure mechanical integrity. For high pressure compressor (HPC), the rotational speed reduces sequentially with degree of hybridization, however component efficiency is not largely affected.
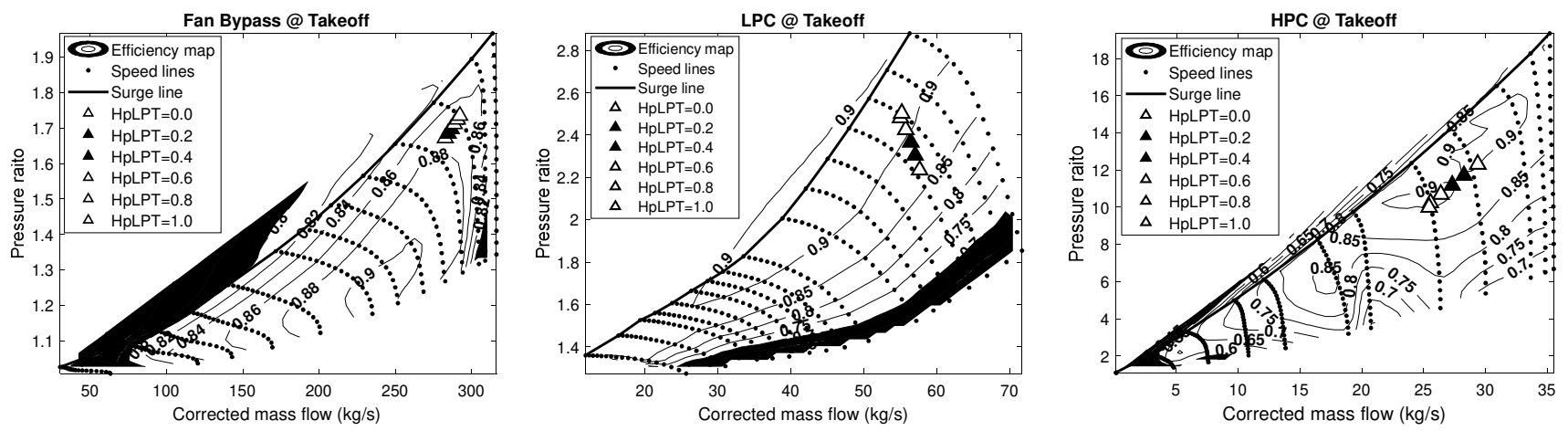

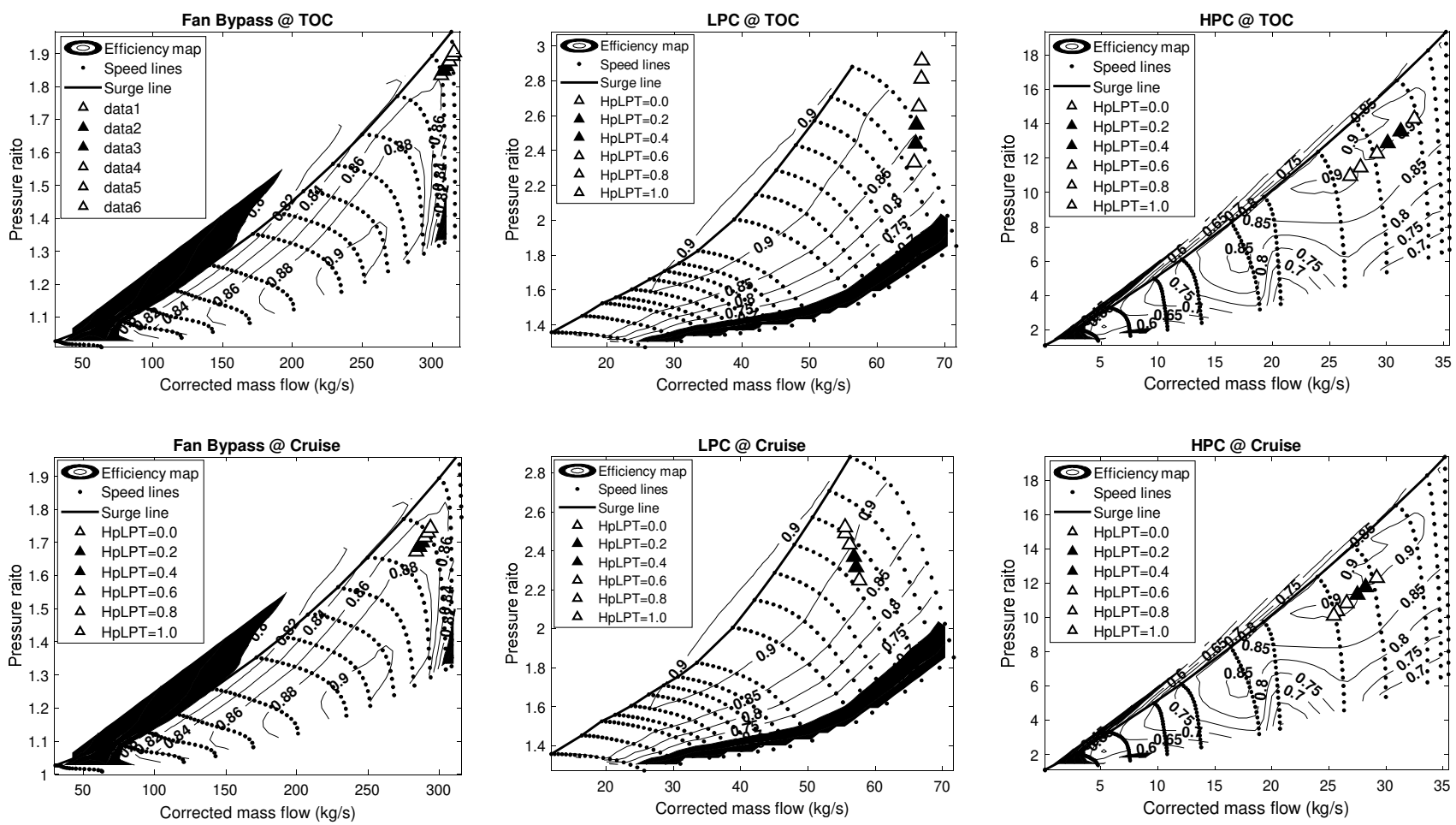

Fig. 8. Gas turbine-electrical powertrain coupling effects

at typical operating conditions

As shown in Fig.9, the electrical power on-take on LP shaft can effectively reduce the fuel flow and further achieve direct combustion emissions reduction compared to the baseline design (conventional engine) at the same thrust demand level. From the perspective of component efficiency, with the increase in degree of hybridization of power, LPC component efficiency is considerably increased by around $4 \%$, while fan bypass component efficiency shows an opposite trend with slight reduction within $1 \%$. And the component efficiency of HPC is not significantly affected by hybridization. In terms of fuel flow rate, a strong linear correlation with negative relationship can be noticeably observed in all three operating conditions. For example, in takeoff condition, fuel flow rate is reduced by $4.24 \%, 8.49 \%, 12.57 \%$, $16.61 \%$ and $21.80 \%$ sequentially with increased hybridization of power on LPT from 0.2 to 1.0. In Top of Climb and Cruise conditions, the fuel flow reduction changes from $4.09 \%, 4.03 \%$ to $20.36 \%$ and $20.11 \%$ approximately with an increment of $4 \%$. Hybridization can achieve fuel saving and reduce direct combustion emissions due to the electrical power on-take and more efficient operation for isolated propulsion system performance analysis. However, it should be highlighted that the aircraft performance is comprehensively determined by aerodynamics, manoeuvre requirement, weight property, and propulsion system performance. The introduction of battery stack and electrical powertrain will increase the aircraft weight and subsequently induce weight-related drag penalty. 

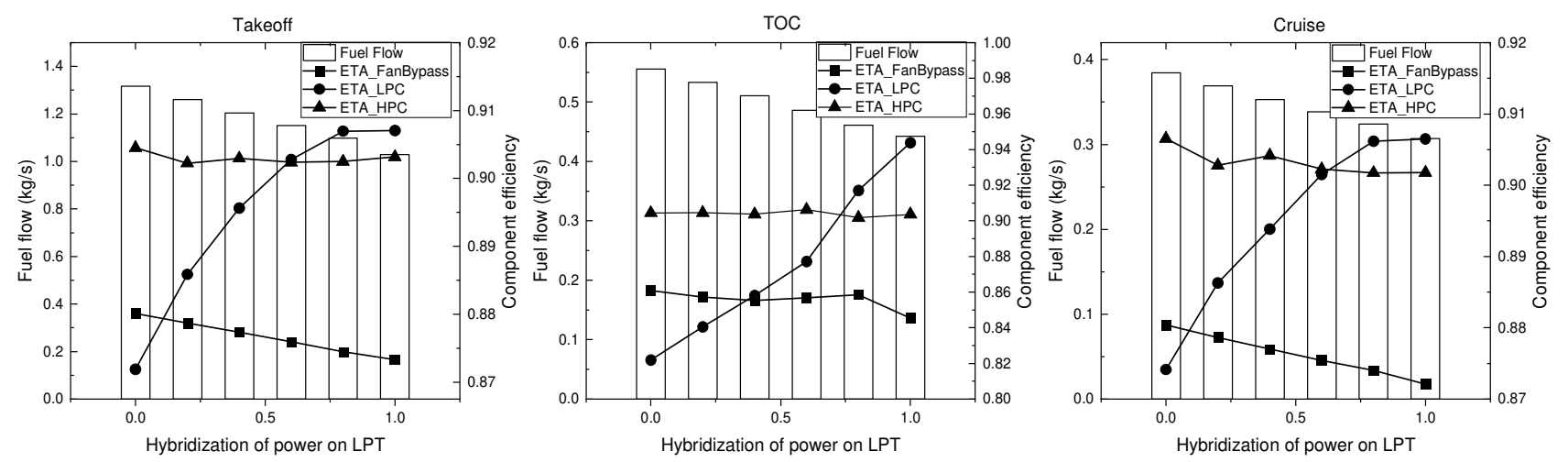

Fig. 9. Performance analysis of parallel hybrid electric propulsion system

\section{Validation of the Proposed MPC-EMS}

In order to validate the effectiveness of the proposed MPC-EMS in terms of block fuel burn, energy consumption, emissions and computational time, equivalent consumption minimization strategy with hard constraints (ECMS-CT), equivalent consumption minimization strategy with penalty function (ECMS-PF) and global Genetic Algorithm-based EMS (global GA-EMS) are respectively simulated to compared with the proposed MPC-EMS.

The instantaneous equivalent fuel consumption in $k$-th flight segment is defined as Equation (28) for ECMS-CT to unify fuel and electricity consumption in a single objective:

$$
\begin{aligned}
& \boldsymbol{u}^{*}(k)=\underset{\boldsymbol{u}(\boldsymbol{k})}{\arg \min }\left\{\boldsymbol{J}(k)=\sum_{m=1}^{M} \dot{W}_{f}^{m}(k) \cdot \delta(k)+\boldsymbol{Q} \cdot \sum_{m=1}^{M} P_{\text {Bat }}^{m}(k) \cdot \delta(k)\right\} \\
&\left\{\begin{array}{l}
\text { s.t. } \boldsymbol{x}(k+1)=\phi(\boldsymbol{x}(k), \boldsymbol{u}(k), k), k \hat{\mathrm{I}} \mathrm{N} \\
N_{C N, \min } \leq N(k) \leq N_{C N, \max } \\
T_{G T, \min } \leq T(k) \leq T_{G T, \max } \\
S O C_{\min } \leq S O C(k) \leq S O C_{\max } \\
W(k) \leq W_{\text {MTOW }}
\end{array}\right.
\end{aligned}
$$

Where $M$ is the number of multiple thrust sources, $\dot{W}_{f}^{m}(k), P_{B a t}^{m}(k)$, and $\delta(k)$ are fuel flow rate, battery power and flight segment duration of the $m$-th thrust sources, $\boldsymbol{Q}$ is the equivalence factor, $T(k), T_{G T, \text { max }}$ and $N(k), N_{C N \text {,max }}$ are gas turbine operating temperature and low pressure shaft non-dimensional rotational speed in $k$-th flight segment and their operating limits, $S O C_{\min }, S O C_{\max }$ are battery SOC limits, $W_{M T O W}$ are aircraft maximum takeoff weight.

For ECMS-PF, the instantaneous equivalent fuel consumption in $k$-th flight segment is modified with penalty function $P F$ as Equation (29):

$$
\boldsymbol{u}^{*}(k)=\underset{\boldsymbol{u}(\boldsymbol{k})}{\arg \min }\left\{\boldsymbol{J}(k)=\sum_{m=1}^{M} \dot{W}_{f}^{m}(k) \cdot \delta(k)+\boldsymbol{P} \boldsymbol{F}(k) \cdot \boldsymbol{Q} \cdot \sum_{m=1}^{M} P_{B a t}^{m}(k) \cdot \delta(k)\right\}
$$




$$
\boldsymbol{P F}(k)=1-\lambda \ln \left(\frac{S O C_{\max }-S O C(k)}{S O C_{\max }-S O C_{\min }}\right)
$$

The equivalence factor $\boldsymbol{Q}$ and penalty function parameter $\lambda$ in ECMS-CT and ECMS-PF are obtained by off-line optimization to minimize mission block fuel burn Equation (30):

$$
\left\{\boldsymbol{Q}^{*}, \boldsymbol{\lambda}^{*}\right\}=\underset{\boldsymbol{Q}, \lambda}{\arg \min }\left\{\sum_{k=1}^{N}\left(\sum_{m=1}^{\boldsymbol{M}} \dot{\boldsymbol{W}}_{\boldsymbol{f}}^{m}(k) \cdot \delta(k)\right)\right\}
$$

The priori flight mission profile we employ is given as a sequence of discrete flight segments including flight phases from take-off to landing, as shown in Fig. 10 and Table VII. The flight mission is divided into 35 discrete flight segments.

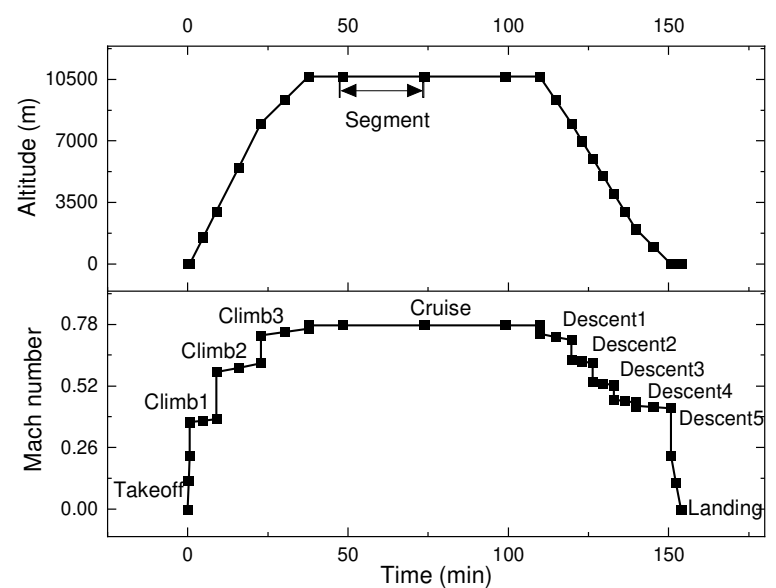

Fig. 10. The prior flight mission profile with discrete flight segments

TABLE VII

FLIGHT MISSION DEFINITION

\begin{tabular}{ccc}
\hline \hline Parameter & Value & Units \\
\hline Cruise Mach number & 0.785 & - \\
Cruise Altitude & 10668.0 & $\mathrm{~m}$ \\
Flight Range & 1000 & $\mathrm{nmi}$ \\
Climb Rate & $6.0 / 6.0 / 3.0$ & $\mathrm{~m} / \mathrm{s}$ \\
Descent Rate & $4.5 / 5.0 / 5.0 / 5.0 / 3.0$ & $\mathrm{~m} / \mathrm{s}$ \\
\hline Battery weight & 10000 & $\mathrm{~kg}$ \\
Battery specific energy & 1000 & $\mathrm{Wh} / \mathrm{kg}$ \\
Battery SOC limits & {$[0.9,0.2]$} & - \\
Motor weight & 500 & $\mathrm{~kg}$ \\
Motor power density & 8 & $\mathrm{~kW} / \mathrm{kg}$ \\
Operating empty weight & 41140 & $\mathrm{~kg}$ \\
Payload & 10000 & $\mathrm{~kg}$ \\
\hline \hline
\end{tabular}


The simulation results of conventional aircraft, hybrid electric aircraft with Global GA-EMS, ECMS-CT, ECMS-PF and the proposed MPC-EMS are shown in Fig. 11, Fig. 12, and Fig. 13. Firstly, a test is carried out to determine the length of prediction horizon. Computational time depends on the length of prediction horizon for MPC optimization. The chosen prediction horizon is expected to compromise the computational time and optimization results of block fuel burn. Therefore, the effect of the length of prediction horizon over the system performance is evaluated. According to the relationship between computational time and block fuel burn cost function with different prediction horizon shown in Fig. 11, the prediction horizon is set as 6 segments, because the block fuel burn is minimized with the prediction horizon of 6 segments, no significant improvement on block fuel burn reduction can be observed with the increase in prediction horizon. However, the computational time largely increases with the increased segment of prediction horizon. Therefore, comprehensively considering the computational efficiency and optimization effect, the prediction horizon is set as 6 segments.

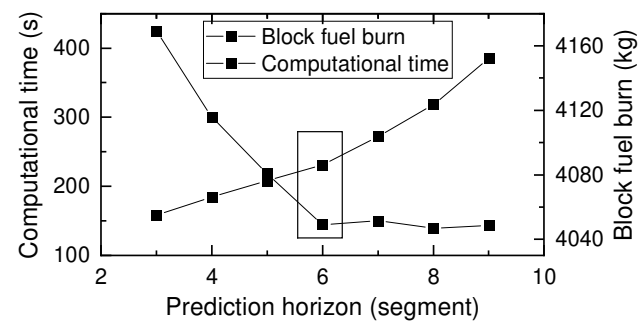

Fig. 11. Computational time and block fuel burn cost versus prediction horizon

In Fig. 12, thrust demand, fuel flow, motor power and battery SOC during flight mission are presented respectively. It can be observed that thrust demand for hybrid electric aircraft is largely increased due to the additional weight of battery and electrical powertrain as well as induced weight-related drag penalty. Especially in the flight phases of climb, and cruise, thrust demand of hybrid electric aircraft is increased by $17.71 \%$ in initial climb and $18.01 \%$ in cruise. Therefore, the potential benefits of gas turbine electrical power on-take and more efficient operation are partially offset by the weight-related lift-induced drag penalty. It can be easily seen that the optimization power split (fuel flow and motor power) obtained by the proposed MPC-EMS is very close to that of global GA-based EMS. And battery SOC operates within $[0.2,0.9]$, which indicates that the electrical energy is well allocated in the whole flight mission to improve the overall efficiency and prevent battery excessive discharge. 

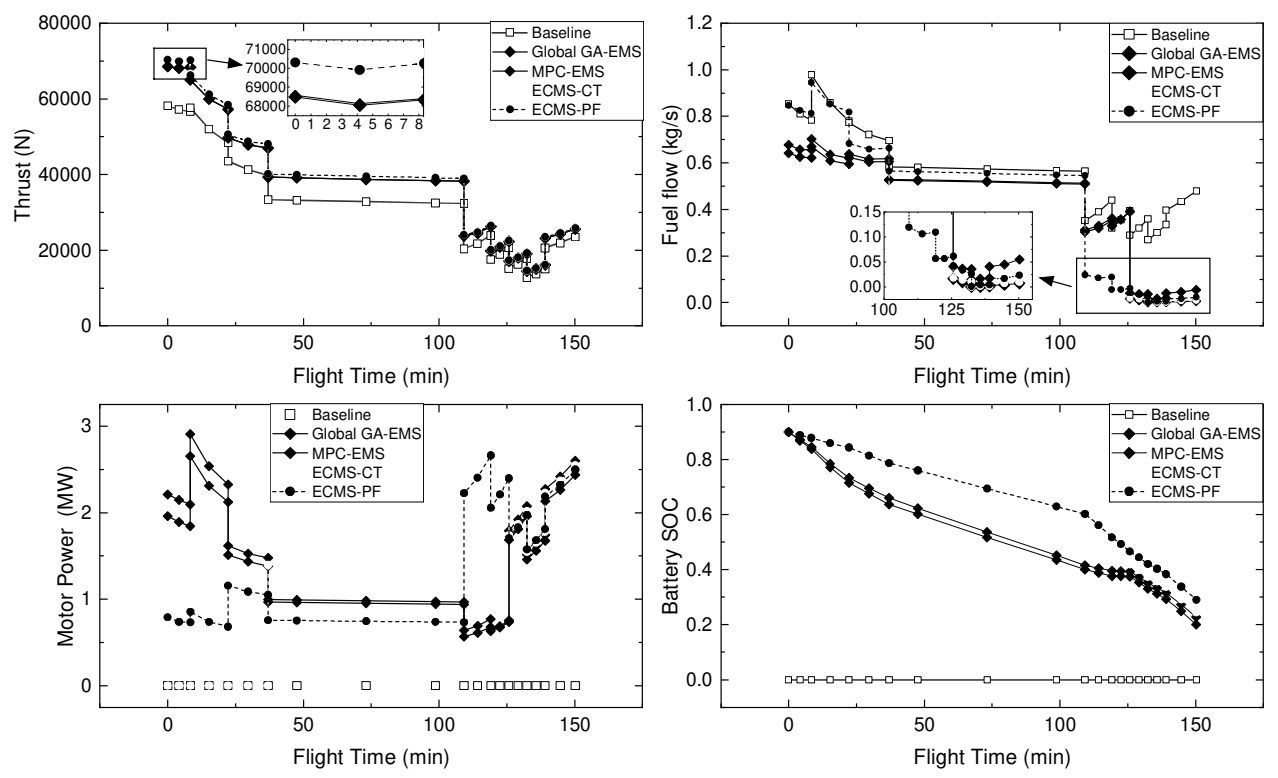

Fig. 12. Performance analysis of conventional aircraft, HEA with global GA-EMS, ECMS-CT, ECMS-PF and MPC-EMS

(X axis: Flight mission duration)

Meanwhile, as shown in Fig. 13, the proposed MPC-EMS can effectively maintain gas turbine temperature limits and LP drive non-dimensional rotational speed to avoid overspeed, ensure a safe operation and a long-term stable work by converting a state-constrained problem into a state-unconstrained problem with penalty function.
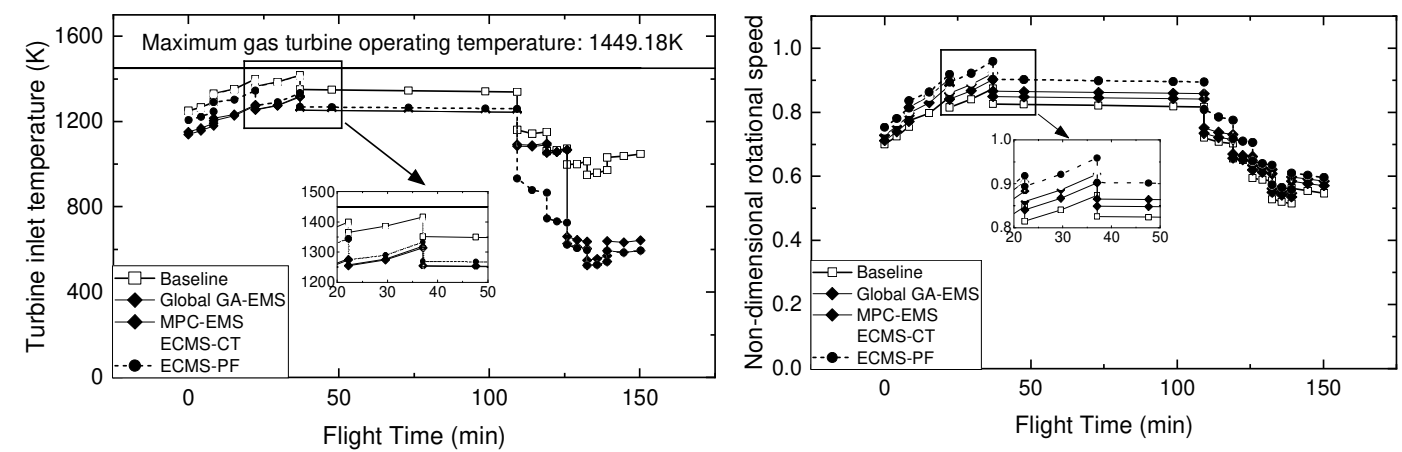

Fig. 13. State constraints (Turbine inlet temperature and non-dimensional rotational speed) in flight mission

As for optimal overall aircraft performance shown in Table VIII, the proposed MPC-EMS can productively reduce block fuel burn by $19.04 \%$ for battery technology level of $1000 \mathrm{Wh} / \mathrm{kg}$. And only a little difference of $1.71 \%$ in terms of optimum block fuel burn can be observed between simulation results of global GA-based EMS and the proposed MPCEMS. This is because MPC-EMS has the ability to anticipate future flight states and can take control actions accordingly. Therefore, hybrid electric aircraft using the proposed MPC-EMS can implement the appropriate power split between gas turbine and electrical powertrain. The optimization performance of ECMS-CT and ECMS-PF is not competitive as the proposed MPC-EMS even the equivalence factor and penalty function parameter are obtained by off-line optimization, 
they can only reduce block fuel burn by $15.03 \%$ and $15.66 \%$ respectively. This is because ECMS-CT and ECMS-PF can only achieve instantaneous optimization in the current flight segment, electrical energy cannot be fully utilized and the effects of current actions on future flight aerodynamics cannot be taken into account.

TABLE VIII

OVERALl AirCRAFT PERFORMANCE OF BLOCK FUEL BURN, ENERgy CONSUMPTION AND EMISSIONS

\begin{tabular}{ccccc}
\hline \hline & Block fuel burn (kg) & Energy consumption (MJ) & $\mathrm{CO}_{2}$ emissions (kg) & NOx emissions (kg) \\
\hline Baseline (conventional aircraft) & 4995.50 & 219302.45 & 15735.82 & 49.22 \\
HEA with Global GA EMS (1000Wh/kg) & 3958.72 & 198987.81 & 13379.96 & 46.16 \\
HEA with MPC-EMS (1000Wh/kg) & 4043.92 & 202728.09 & 13648.34 & 46.77 \\
HEA with ECMS-CT (1000Wh/kg) & 4244.56 & 209736.18 & 14215.36 & 47.98 \\
HEA with ECMS-PF (1000Wh/kg) & 4213.13 & 206916.41 & 14064.35 & 47.07 \\
\hline \hline
\end{tabular}

The computational time of Global GA-based EMS and the proposed MPC EMS is compared in Table IX. The simulation is carried out on an Intel(R) Core(TM) i7-9750 PU (2.60 GHz) command in Python 3.7. It can be observed that the proposed strategy can effectively speed up the running time by $98.21 \%$ compared with global GA-based EMS. Although the runtime of ECMS-PF is slightly less than MPC-EMS, the optimization performance of ECMS-PF is not competitive as the proposed MPC-EMS. Moreover, the optimization performance of ECMS-PF is highly dependent on equivalence factor and penalty function parameter which is obtained by off-line optimization, so it is highly sensitive to flight mission profile.

TABLE IX

RuNTIME OF GLOBAL GA-EMS, ECMS-CT, ECMS-PF AND MPC-EMS

\begin{aligned} & \hline \hline Runtime (s) \\ & \hline Global GA EMS $(1000 \mathrm{Wh} / \mathrm{kg}) 12905.92 \\ &$ MPC-EMS $(1000 \mathrm{Wh} / \mathrm{kg}) 231.10 \\ &$ ECMS-CT $(1000 \mathrm{Wh} / \mathrm{kg}) 924.67 \\ &$ ECMS-PF $(1000 \mathrm{Wh} / \mathrm{kg}) 165.46 \\ &$\hline\end{aligned}

D. Sensitivity analysis of battery technology level

To investigate the effect of battery technology level on hybrid electric aircraft performance, sensitivity analysis is conducted by assuming battery specific energy to be $500 \mathrm{Wh} / \mathrm{kg}, 1000 \mathrm{Wh} / \mathrm{kg}$, and $1500 \mathrm{Wh} / \mathrm{kg}$ respectively in Fig. 14 
(a)-(c). Fig. 14 (d) summarizes and compares the overall aircraft performance in terms of block fuel burn, $\mathrm{CO}_{2}$ emissions and NOx emissions.

According to the relationship between computational time and block fuel burn with different prediction horizons, the prediction horizon is set as 7, 6, 6 segments respectively for three cases. As shown in Fig. 14 (d), the proposed MPCEMS can reduce block fuel burn by $2.42 \%, 19.04 \%$, and $34.58 \%$ for battery technology level of $500 \mathrm{Wh} / \mathrm{kg}$, 1000 $\mathrm{Wh} / \mathrm{kg}$, and $1500 \mathrm{Wh} / \mathrm{kg}$ respectively. And only a little difference of $0.37 \%, 1.71 \%$, and $1.75 \%$ in terms of optimum block fuel burn can be observed between simulation results of global GA-based EMS and the proposed MPC-EMS. The potential benefits of $\mathrm{CO}_{2}$ emissions reduction do not follow the block fuel burn reduction, because the $\mathrm{CO}_{2}$ emissions for electrical energy production is considered. Hybridization can greatly reduce the $\mathrm{CO}_{2}$ emissions by $13.26 \%$ and $25.9 \%$ with battery specific energy of $1000 \mathrm{Wh} / \mathrm{kg}$ and $1500 \mathrm{Wh} / \mathrm{kg}$ due to lower emission index for ground-based power plants. However, when battery specific energy is at $500 \mathrm{Wh} / \mathrm{kg}$, the benefit of $\mathrm{CO}_{2}$ emission reduction cannot be achieved because thrust demand is increased accordingly due to induced weight and drag penalty, and direct carbon emission reduction caused by gas turbine electrical power on-take is compromised by the ground emissions from electricity generation. Similarly, NOx emissions can be reduced by $4.97 \%$ and $15.33 \%$ with battery specific energy of $1000 \mathrm{Wh} / \mathrm{kg}$ and $1500 \mathrm{Wh} / \mathrm{kg}$ due to block fuel burn reduction and more efficient gas turbine operation. As for battery technology level of $500 \mathrm{Wh} / \mathrm{kg}$, the benefit of block fuel burn reduction is not capable of offsetting the NOx emissions from gas turbine operation with high thrust demand and associated $\mathrm{T}_{3}$ and $\mathrm{P}_{3}$, thus no benefits of $\mathrm{NOx}$ emissions can be expected. From the optimization results, it can be observed that with limited electrical energy available onboard, consumable energy (fuel) is expected to be used in initial stages while non-consumable energy (battery electrical energy) is suggested to be allocated in the final flight phases, such as descent and landing. This is because at integrated aircraft level, using consumable energy in initial stages can relatively reduce aircraft weight and avoid drag penalty in flight. In addition, electrical powertrain is optimally utilized to enhance overall propulsion system performance when gas turbine operates at low efficiency. Therefore, optimal energy management strategy is a balance between improvements on gas turbine specific fuel consumption and sizing induced weight and drag penalty. 

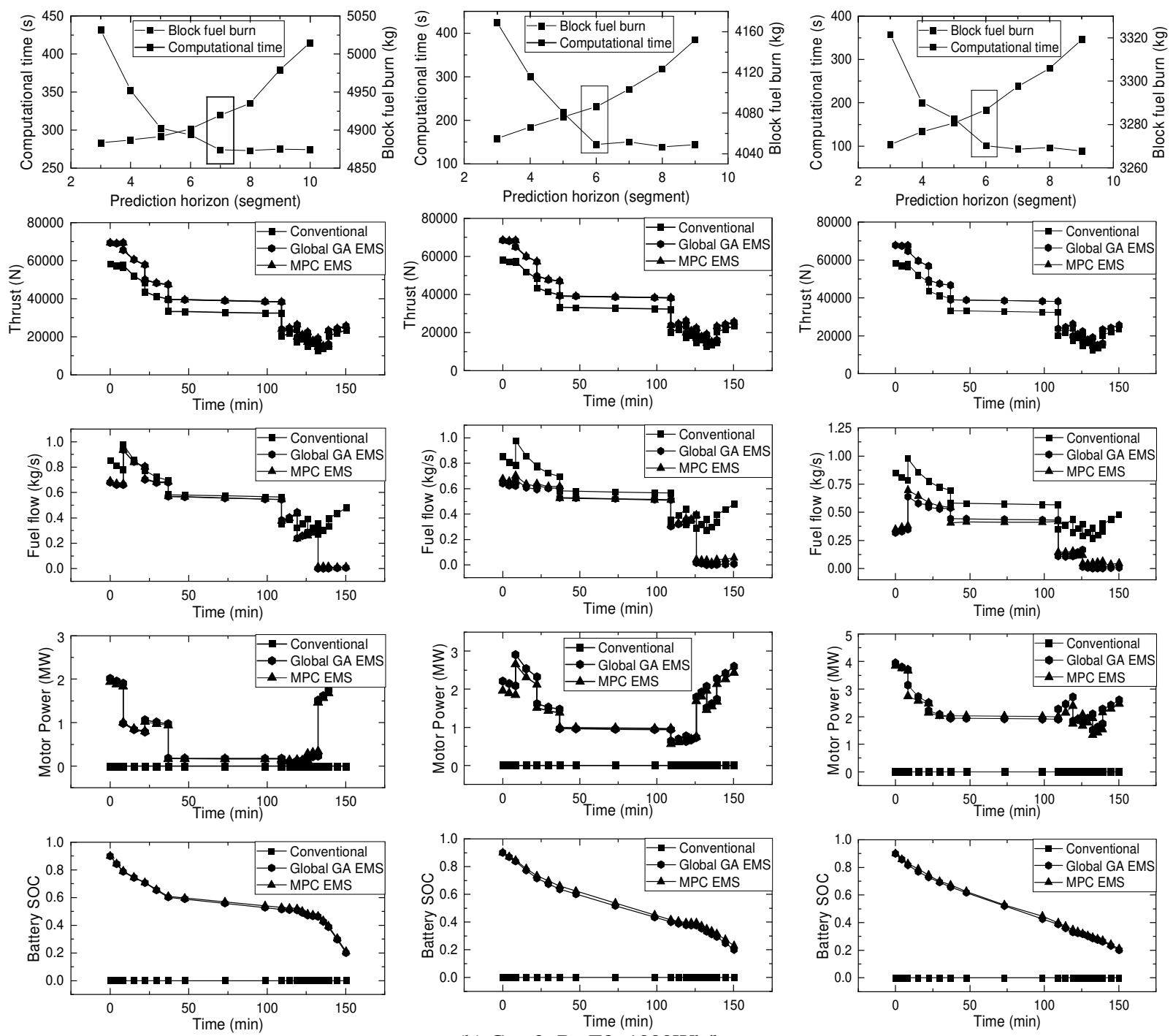

(a) Case1: BatE1=500Wh/kg

(b) Case2: BatE2=1000Wh/kg

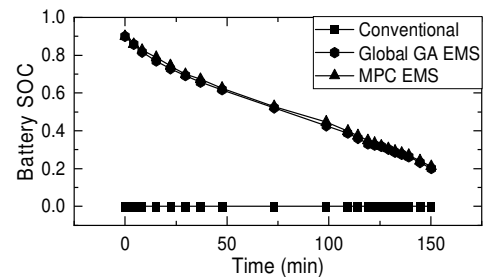

(c) Case3: BatE3=1500Wh/kg

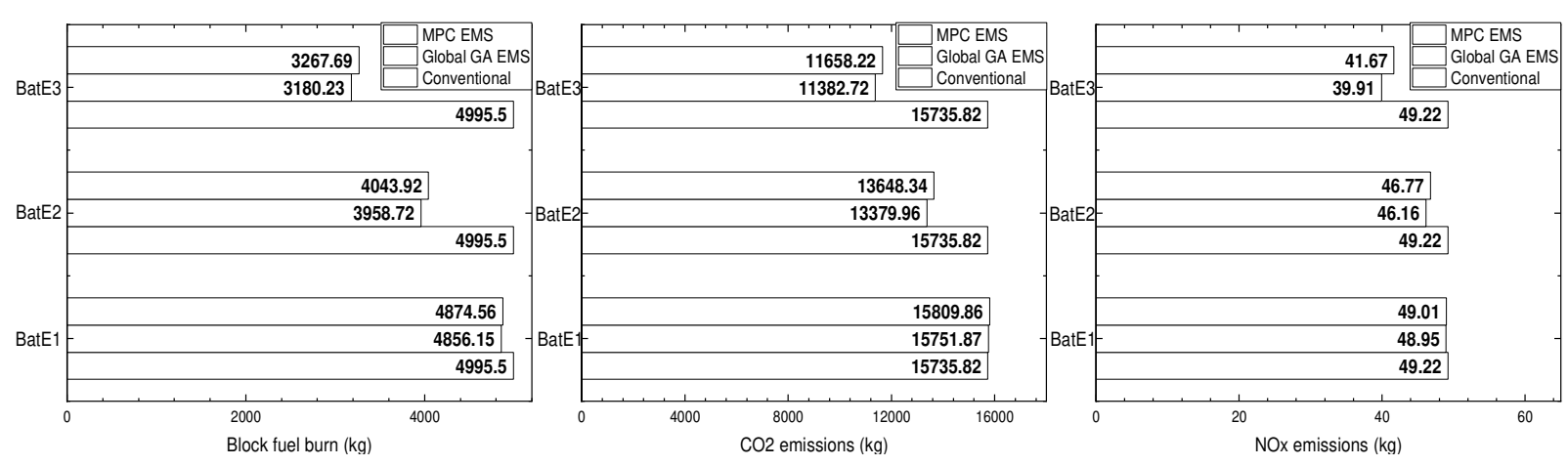

(d) Block fuel burn and emissions for the flight mission

Fig. 14. Sensitivity analysis of battery technology level

In Table X, the proposed strategy can dramatically speed up the running time by $97.64 \%, 98.21 \%$ and $98.35 \%$ for battery technology level of $500 \mathrm{Wh} / \mathrm{kg}, 1000 \mathrm{Wh} / \mathrm{kg}$ and $1500 \mathrm{Wh} / \mathrm{kg}$ respectively. 
TABLE X

RUNTIME OF GLOBAL GA OPTIMIZATION EMS AND MPC-EMS

\begin{tabular}{cl}
\hline \hline & Runtime (s) \\
\hline Global GA EMS $(500 \mathrm{Wh} / \mathrm{kg})$ & 16604.79 \\
MPC-EMS $(500 \mathrm{Wh} / \mathrm{kg})$ & 319.59 \\
Global GA EMS $(1000 \mathrm{Wh} / \mathrm{kg})$ & 12905.92 \\
MPC-EMS $(1000 \mathrm{Wh} / \mathrm{kg})$ & 231.10 \\
Global GA EMS $(1500 \mathrm{Wh} / \mathrm{kg})$ & 11142.11 \\
MPC-EMS $(1500 \mathrm{Wh} / \mathrm{kg})$ & 183.78 \\
\hline \hline
\end{tabular}

Therefore, according to the above results analysis, the proposed MPC-EMS can effectively reduce the block fuel burn and emissions as global GA-based EMS meanwhile effectively saving the computational time on the same computing platform.

\section{CONCLUSION}

In this paper, the Nonlinear MPC based optimal energy management scheme has been proposed to minimize the block fuel burn, energy consumption, and emissions during flight mission. Firstly, the ANN model has been adopted with backpropagation algorithm to predict turbofan engine performance with high accuracy and computational efficiency. And the gas turbine-electrical powertrain coupling effects have been investigated by analysing gas turbine components pressure build-up, core/bypass mass flow, and component efficiency at typical operating conditions of takeoff, TOC and cruise. It can be concluded that hybridization can achieve fuel saving and reduce direct combustion emissions due to the electrical power on-take and component efficiency improvement for isolated propulsion system. Then, by combining a point-mass aircraft dynamic model and electrical powertrain characteristics, nonlinear model predictive control with Cross-Entropy Method has been employed to obtain optimal energy management strategy considering coupled propulsionaerodynamics. The backward induction algorithm has been applied to achieve energy balance where energy onboard should be equal to mission energy demand, as excessive amount of energy carried induces weight and drag penalty. And the state-constrained problems are converted into the state-unconstrained problems with penalty function to avoid battery over-discharge and maintain gas turbine operating limits but effectively reduce computational load. Finally, the proposed MPC-EMS has been verified by simulation studies and compared with global GA-based EMS, ECMS-CT, and ECMSPF. The simulation results indicate that the proposed MPC-EMS can effectively reduce block fuel burn by $2.42 \%$, $19.04 \%$, and $34.58 \%$ for battery technology level of $500 \mathrm{Wh} / \mathrm{kg}, 1000 \mathrm{Wh} / \mathrm{kg}$, and $1500 \mathrm{Wh} / \mathrm{kg}$ respectively. The 
proposed MPC-EMS can dramatically reduce the computational time by more than $97 \%$ compared with Global GAbased EMS while achieving similar optimization performance of block fuel burn reduction and emissions reduction.

\section{REFERENCE:}

[1] Viswanathan, V., \& Knapp, B. M. (2019). Potential for electric aircraft. Nature Sustainability, 2(2), 88-89.

[2] Schäfer, A. W., Barrett, S. R., Doyme, K., Dray, L. M., Gnadt, A. R., Self, R., ... \& Torija, A. J. (2019). Technological, economic and environmental prospects of all-electric aircraft. Nature Energy, 4(2), 160-166.

[3] Brelje, B. J., \& Martins, J. R. (2019). Electric, hybrid, and turboelectric fixed-wing aircraft: A review of concepts, models, and design approaches. Progress in Aerospace Sciences, 104, 1-19.

[4] National Academies of Sciences, Engineering, and Medicine. (2016). Commercial aircraft propulsion and energy systems research: reducing global carbon emissions. National Academies Press.

[5] Martinez, C. M., Hu, X., Cao, D., Velenis, E., Gao, B., \& Wellers, M. (2016). Energy management in plug-in hybrid electric vehicles: Recent progress and a connected vehicles perspective. IEEE Transactions on Vehicular Technology, 66(6), 4534-4549.

[6] C. Sun, F. Sun, and H. He, "Investigating adaptive-ECMS with velocity forecast ability for hybrid electric vehicles,” Appl. Energy, vol. 185, pp. 1644-1653, 2017.

[7] Larsson, V., Johannesson, L., \& Egardt, B. (2014). Analytic solutions to the dynamic programming subproblem in hybrid vehicle energy management. IEEE Transactions on Vehicular Technology, 64(4), 1458-1467.

[8] Liu, J., Chen, Y., Zhan, J., \& Shang, F. (2019). Heuristic dynamic programming based online energy management strategy for plug-in hybrid electric vehicles. IEEE Transactions on Vehicular Technology, 68(5), 4479-4493.

[9] Liu, J., Chen, Y., Li, W., Shang, F., \& Zhan, J. (2017). Hybrid-trip-model-based energy management of a PHEV with computation-optimized dynamic programming. IEEE Transactions on Vehicular Technology, 67(1), 338353.

[10]Nguyễn, B. H., Vo-Duy, T., Ta, M. C., \& Trovão, J. P. F. (2021). Optimal Energy Management of Hybrid Storage Systems Using an Alternative Approach of Pontryagin's Minimum Principle. IEEE Transactions on Transportation Electrification.

[11]East, S., \& Cannon, M. (2019). Energy management in plug-in hybrid electric vehicles: Convex optimization algorithms for model predictive control. IEEE Transactions on Control Systems Technology, 28(6), 2191-2203. 
[12] Yang, C., You, S., Wang, W., Li, L., \& Xiang, C. (2019). A stochastic predictive energy management strategy for plug-in hybrid electric vehicles based on fast rolling optimization. IEEE Transactions on Industrial Electronics, 67(11), 9659-9670.

[13]Pereira, D. F., da Costa Lopes, F., \& Watanabe, E. H. (2020). Nonlinear Model Predictive Control for the Energy Management of Fuel Cell Hybrid Electric Vehicles in Real Time. IEEE Transactions on Industrial Electronics, 68(4), 3213-3223.

[14]He, H., Quan, S., Sun, F., \& Wang, Y. X. (2020). Model predictive control with lifetime constraints based energy management strategy for proton exchange membrane fuel cell hybrid power systems. IEEE Transactions on Industrial Electronics, 67(10), 9012-9023.

[15] Sahoo, S., Zhao, X., \& Kyprianidis, K. (2020). A Review of Concepts, Benefits, and Challenges for Future Electrical Propulsion-Based Aircraft. Aerospace, 7(4), 44.

[16] Silva, H. L., \& Guimarães, T. A. (2020). Conceptual Design of a Thin-Haul Aircraft by Energy Sizing Optimization Including Aero-Propulsive Interactions. In AIAA Scitech 2020 Forum (p. 1503).

[17] Perullo, C., \& Mavris, D. (2014). A review of hybrid-electric energy management and its inclusion in vehicle sizing. Aircraft Engineering and Aerospace Technology: An International Journal.

[18]Riboldi, C. E. (2019). Energy-optimal off-design power management for hybrid-electric aircraft. Aerospace Science and Technology, 95, 105507.

[19] Riboldi, C. E. (2019). Energy-optimal off-design power management for hybrid-electric aircraft. Aerospace Science and Technology, 95, 105507.

[20] Nakka, S. K. S., \& Alexander-Ramos, M. J. (2021). Simultaneous combined optimal design and control formulation for aircraft hybrid-electric propulsion systems. Journal of Aircraft, 58(1), 53-62.

[21]Xie, Y., Savvaris, A., \& Tsourdos, A. (2019). Fuzzy logic based equivalent consumption optimization of a hybrid electric propulsion system for unmanned aerial vehicles. Aerospace Science and Technology, 85, 13-23.

[22] Donateo, T., Ficarella, A., \& Spedicato, L. (2018). Applying dynamic programming algorithms to the energy management of hybrid electric aircraft. In ASME Turbo Expo 2018: Turbomachinery Technical Conference and Exposition. American Society of Mechanical Engineers Digital Collection.

[23]Donateo, T., De Pascalis, C. L., Strafella, L., \& Ficarella, A. (2021). Off-line and on-line optimization of the energy management strategy in a Hybrid Electric Helicopter for urban air-mobility. Aerospace Science and Technology, 113, 106677. 
[24]Doff-Sotta, M., Cannon, M., \& Bacic, M. (2021). Optimal energy management for hybrid electric aircraft. IFAC-PapersOnLine, 53(2).

[25] Ang, A. W. X., Gangoli Rao, A., Kanakis, T., \& Lammen, W. (2019). Performance analysis of an electrically assisted propulsion system for a short-range civil aircraft. Proceedings of the Institution of Mechanical Engineers, Part G: Journal of Aerospace Engineering, 233(4), 1490-1502.

[26]Zamboni, J., Vos, R., Emeneth, M., \& Schneegans, A. (2019). A method for the conceptual design of hybrid electric aircraft. In AIAA Scitech 2019 Forum (p. 1587).

[27] Seitz, A., Nickl, M., Stroh, A., \& Vratny, P. C. (2018). Conceptual study of a mechanically integrated parallel hybrid electric turbofan. Proceedings of the Institution of Mechanical Engineers, Part G: Journal of Aerospace Engineering, 232(14), 2688-2712.

[28]Electrified Aircraft Propulsion (EAP) for Larger Aircraft. Available at: https://www1.grc.nasa.gov/aeronautics/eap/larger-aircraft/aircraft-configurations-technologies/hybrid-electric/.

[29] Hull, D. G. (2007). Fundamentals of airplane flight mechanics (Vol. 19). Berlin: Springer.

[30] Kurzke, J., \& Halliwell, I. (2018). Propulsion and power: an exploration of gas turbine performance modelling. Cham, Switzerland: Springer international publishing.

[31]Park, Y., Choi, M., Kim, K., Li, X., Jung, C., Na, S., \& Choi, G. (2020). Prediction of operating characteristics for industrial gas turbine combustor using an optimized artificial neural network. Energy, 213, 118769.

[32]Lv, C., Xing, Y., Zhang, J., Na, X., Li, Y., Liu, T., ... \& Wang, F. Y. (2017). Levenberg-Marquardt backpropagation training of multilayer neural networks for state estimation of a safety-critical cyber-physical system. IEEE Transactions on Industrial Informatics, 14(8), 3436-3446.

[33]Liu, Z., \& Karimi, I. A. (2020). Gas turbine performance prediction via machine learning. Energy, 192, 116627.

[34] McDonald, R. A. (2014). Electric propulsion modelling for conceptual aircraft design. In 52nd Aerospace Sciences Meeting (p. 0536).

[35] Bradley, M. K., \& Droney, C. K. (2015). Subsonic ultra green aircraft research: Phase 2. Volume 2; hybrid electric design exploration. Available at: https://ntrs.nasa.gov/archive/nasa/casi.ntrs.nasa.gov/20150017039.pdf

[36] Kyprianidis, K. G., Nalianda, D., \& Dahlquist, E. (2015). A NOx emissions correlation for modern RQL combustors. Energy Procedia, 75, 2323-2330.

[37] UK Carbon Intensity API. Available at: https://carbonintensity.org.uk/ 
[38]He, H., Quan, S., Sun, F., \& Wang, Y. X. (2020). Model predictive control with lifetime constraints-based energy management strategy for proton exchange membrane fuel cell hybrid power systems. IEEE Transactions on Industrial Electronics, 67(10), 9012-9023.

[39]Wen, M., \& Topcu, U. (2020). Constrained cross-entropy method for safe reinforcement learning. IEEE Transactions on Automatic Control.

[40] de Magalhães Carvalho, L., da Silva, A. M. L., \& Miranda, V. (2018). Security-constrained optimal power flow via cross-entropy method. IEEE Transactions on Power Systems, 33(6), 6621-6629.

[41]He, D., Lee, L. H., Chen, C. H., Fu, M. C., \& Wasserkrug, S. (2010). Simulation optimization using the crossentropy method with optimal computing budget allocation. ACM Transactions on Modelling and Computer Simulation (TOMACS), 20(1), 1-22.

[42]CFM56-7 Technical characteristics. Available at: https://www.safran-aircraft-engines.com/commercialengines/single-aisle-commercial-jets/cfm56/cfm56-7b 
$2021-12-21$

Nonlinear model predictive

control-based optimal energy

management for hybrid electric aircraft

considering aerodynamics-propulsion

coupling effects

Zhang, Jinning

IEEE

Zhang J, Roumeliotis I, Zolotas A. (2022) Nonlinear model predictive control-based optimal energy management for hybrid electric aircraft considering aerodynamics-propulsion coupling effects. IEEE Transactions on Transportation Electrification, Volume 8, Number 2, June 2022, pp. 2640-2653

https://doi.org/10.1109/TTE.2021.3137260

Downloaded from Cranfield Library Services E-Repository 